University of Rhode Island

DigitalCommons@URI

Open Access Dissertations

1991

\title{
Transformational and Transactional Church Leadership Perspectives of Pastors and Parishioners - An Extension
}

James L. Bray

University of Rhode Island

Follow this and additional works at: https://digitalcommons.uri.edu/oa_diss

\section{Recommended Citation}

Bray, James L., "Transformational and Transactional Church Leadership Perspectives of Pastors and Parishioners - An Extension" (1991). Open Access Dissertations. Paper 969.

https://digitalcommons.uri.edu/oa_diss/969

This Dissertation is brought to you for free and open access by DigitalCommons@URI. It has been accepted for inclusion in Open Access Dissertations by an authorized administrator of DigitalCommons@URI. For more information, please contact digitalcommons-group@uri.edu. 


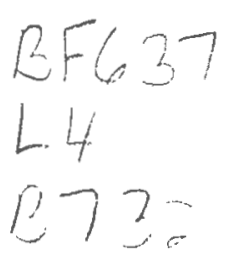

TRANSFORMATIONAL AND TRANSACTIONAL $\mid 4$,

CHURCH LEADERSHIP PERSPECTIVES

OF PASTORS AND PARISHIONERS-

AN EXTENSION

BY

JAMES L. BRAY

A DISSERTATION SUBMITTED IN PARTIAL FULFILLMENT OF THE

REQUIREMENTS FOR THE DEGREE OF

DOCTOR OF PHILOSOPHY

IN

PSYCHOLOGY

UNIVERSITY OF RHODE ISLAND

1991

$26-32156$ 


\begin{abstract}
There is a gap between a theoretically ideal pastoral term (ten years) and the more frequently observed term of less than three years. This study is part of a series of studies undertaken to determine 1) whether pastors and parishioners differ in their expectations of church leadership along Transformational and Transactional lines, 2) whether that difference is associated with tension in pastor/parishioner relations, and 3) whether that tension causes pastors to have brief tenures.
\end{abstract}

This research operationalizes and extends the Transformational and Transactional leadership perspectives into a religious setting. A review of the social science literature, as well as, the Biblical literature suggested the particular importance of the Transformational leader providing a Model, being involved in a wide Breadth of interests, and Persevering. The Transactional leader, on the other hand, is less concerned about providing an example, is interested only in a few specific areas, and is likely to conform. The first hypothesis was that pastors would respond more Transformationally relative to parishioners regarding this basic leadership distinction. This basic distinction was addressed through a Likert-type scale in which participants described a "successful pastor" and an "unsuccessful pastor"; as hypothesized pastors describe "successful pastors" more Transformationally than do parishioners and parishioners describe "unsuccessful pastors" more Transformationally than do pastors. Three sub-dimensions of Transformationalism (Modeling, Perseverance, and Breadth of Involvement) developed for this series of studies were also investigated; the second hypothesis was that pastors would respond more Transformationally relative to parishioners on these sub-dimensions. The second hypothesis was not supported. The third hypothesis was that parishioners more frequently than pastors would relate Transactional rather than Transformational behaviors to reduced tensions; i.e., that parishioners more often than pastors would see pastors' emphasis on Transformational concerns rather than the parishioners' Transactional needs resulting in tension. The third hypothesis, which was addressed through an open- ended question, was supported. Responses elsewhere in the questionnaire are compared to the responses to the open-ended question in a qualitative way; this comparison, which provides data on pastor/parishioner tension, was pursued without hypothesis. Finally, pastor/parishioner views on a sub-set of the Modeling sub-dimension, a "love factor", were clarified. 


\section{ACKNOWLEDGEMENTS}

First, I thank my wife and co-coder, Lynn, for her encouragement and assistance.

Second, I thank my committee for their time, attention, and support. Special thanks to Dr. Albert Lott-teacher, adviser, and friend; he guided me through the early research and patiently saw me through the project. Dr. Sandra Ketrow is to be thanked for sharing her background in leadership research and for her challenge for completeness. I thank Dr. Roger Mitchell for asking tough questions and for insisting on quality.

Third, I thank the pastors and parishioners who sincerely and thoroughly responded to the questionnaire.

Fourth, I thank God for the opportunity to further the ministry He has given me and potentially to further the ministries of several pastors and congregations. 


\section{PREFACE}

This study is part of a series which attempts to discover and understand the differences between pastors and parishioners in their expectations of church leadership along Transformational and Transactional lines. Transformational leaders concern themselves with those things necessary for the organization, people, and/or product (or program) to reach potential; Transactional leaders concern themselves with what is necessary to maintain the status quo. This study will utilize a questionnaire to survey pastors and parishioners within my denomination, Conservative Baptists of America, in the Northeast. It is assumed that Transformational/Transactional leadership differences lead to tensions between pastors and parishioners that may ultimately influence pastoral tenure and effectiveness. This line of inquiry may eventually help account for the gap between a theoretically ideal pastoral term (ten years) and the more frequently observed term of less than three years.

Personally, as a minister I am interested in facilitating cooperation between pastors and congregations. As a student of psychology I am interested in testing the Transformational/Transactional leadership distinctions on a specific population. Leadership is important; dynamic and effective leadership separates successful from unsuccessful organizations according to Hersey and Blanchard (1972; p. 67). Gibbons (1986, p. 3) cites Levinson and Rosenthal (1984, p. 4) as saying, "All factors being equal, the most significant difference between one organization and another is neither sociological nor economic. Rather, it lies in a leadership style that gives direction, evolves structure, and allocates power." 
Abstract

Acknowledgements iii

Preface iv

Table of Contents

List of Tables and Appendices vii

Overview of Leadership Studies

Historical Perspective

Contemporary Views

Principal Literature and Definitions

Transformational and Transactional Leadership

$\begin{array}{ll}\text { Leadership in the Church } & 11\end{array}$

$\begin{array}{ll}\text { Biblical Concepts of Leadership } & 12\end{array}$

$\begin{array}{lr}\text { Assumptions and Hypotheses } & 15\end{array}$

$\begin{array}{ll}\text { Method } & 18\end{array}$

$\begin{array}{ll}\text { Introduction } & 18\end{array}$

$\begin{array}{ll}\text { Development of the Questionnaire } & 18\end{array}$

$\begin{array}{ll}\text { Participants } & 22\end{array}$

$\begin{array}{ll}\text { Procedure } & 22\end{array}$

$\begin{array}{ll}\text { Coding } & 23\end{array}$

$\begin{array}{lr}\text { Results } & 27\end{array}$

The Basic Transformational/Transactional Distinction

$\begin{array}{ll}\text { Investigated through the } 46 \text { Statements } & 27\end{array}$

The Basic Transformational/Transactional Distinction and the

Three Transformational Sub-Dimensions $\quad 45$

The Open-Ended Question on Tension $\quad 47$ 
Table Of Contents (cont.)

$\begin{array}{lr}\text { Discussion } & 51\end{array}$

$\begin{array}{ll}\text { Introduction } & 51\end{array}$

$\begin{array}{ll}\text { Internal Consistency of PCAs } & 51\end{array}$

The Basic Transformational/Transactional Distinction 52

The Three Transformational Sub-Dimensions 56

$\begin{array}{lc}\text { Tensions and Transformational/Transactional } & 58\end{array}$

The Open-Ended Question and The PCA Factors 59

$\begin{array}{ll}\text { The Love Factor } & 61\end{array}$

$\begin{array}{ll}\text { Limitations } & 63\end{array}$

$\begin{array}{ll}\text { Conclusion } & 64\end{array}$

$\begin{array}{ll}\text { Appendices } & 66\end{array}$

$\begin{array}{ll}\text { Bibliography } & 80\end{array}$ 


\section{List Of Tables And Appendices}

Tables

(Pages)

Table 1-Mean and Standard Deviation Scores For The PCA Items 30

Table 2-_"Successful Pastor" Factor Labels and Loadings 33

Table 3_"Unsuccessful Pastor" Factor Labels and Loadings _ . 34

Table 4-Cronbach's Coefficient Alpha For the "Successful Pastor" 35

Table 5-Cronbach's Coefficient Alpha For the "Unsuccessful Pastor" 37

Table 6-t-tests Comparing "Successful" With "Unsuccessful" Pastors 42

Table 7-Least Square Means for the "Love Factor" Items 43

Table 8- $t$-tests for the "Love Factor" Items 46

Table 9--Tension Categories $\quad 49$

$\begin{array}{ll}\text { Appendices } & \text { (Pages) }\end{array}$

$\begin{array}{ll}\text { Appendix 1-Questionnaire } & 66\end{array}$

Appendix 2-Transformational/Transactional Contrasts from

$\begin{array}{ll}\text { Earlier Coding Manual } & 72\end{array}$

$\begin{array}{ll}\text { Appendix 3-Pairs of Contrasting Statements } & 73\end{array}$

$\begin{array}{ll}\text { Appendix 4-Informed Consent } & 74\end{array}$

$\begin{array}{ll}\text { Appendix 5-Coding Check Instructions } & 75\end{array}$

Appendix 6-Klubnik's (1984) Frustrations with Pastoral Ministry 79 


\section{OVERVIEW OF LEADERSHIP STUDIES}

Historical Perspective

Stogdill's Handbook of Leadership (Bass, 1981) is the standard from which we understand the concepts of leader and leadership. Leadership is a universal concept. Leadership has many definitions; Bass (1981) says, "There are almost as many different definitions of leadership as there are persons who have attempted to define the concept." Bass goes on to list eleven classes of definitions:

Leadership as a Focus of Group Process

Leadership as Personality and Its Effects

Leadership as the Art of Inducing Compliance

Leadership as the Exercise of Influence

Leadership as Act of Behavior

Leadership as a Form of Persuasion

Leadership as a Power Relation

Leadership as an Instrument of Goal Achievement

Leadership as an Emerging Effect of Interaction

Leadership as a Differentiated Role

Leadership as the Initiation of Structure (pp. 7ff).

Bass (1981) also lists ten kinds of leadership theory:

Great-Man Theories

Trait Theories

Environmental Theories

Personal-Situational Theories

Psychoanalytical Theories

Interaction-Expectation Theories

Humanistic Theories

Exchange Theories

Behavioral Theories

Perceptual and Cognitive Theories (pp. 26ff).

As a universal concept, leadership has been studied in ancient times in many civilizations. The historical books of the Old Testament, for instance, time and again refer to family leaders (patriarchs), judicial leaders (elders and judges), military leaders (like Joshua), political leaders (kings), and religious leaders (priests and prophets). Our ancestors found leadership to be controversial, as we do; Andriessen and Drenth $(1984$, p. 481) offer the following from the Chinese book of wisdom Tao Te King (600 B.C.): "most leaders are despised, some leaders are feared, few leaders are praised, and the rare good leader is never 
noticed." Despite the many definitions of leadership that history has afforded us, no theory or concept of leadership has come into modern times with wide appeal. My working definition of leadership is working to promote the motivation of a group to use its resources to discover and meet needs.

\section{Contemporary Views}

What are some of the major, current approaches to studying leadership? Gordon (1987) lists five: the trait perspective, the behavioral view, the situational models, the attributional model, and the operant conditioning model. Hollander's (1985) review listed the "hereditary and instinct" approach, as well; he said: "The idea that 'leaders are born, not made' still has wide appeal, even though it has been largely discredited" (p. 490). The trait perspective (we should evaluate leaders by personality and social traits and physical characteristics) and one of the situational models, the Fiedler Contingency Theory (effective leadership style is dependent upon the situation), have received the most interest. Concerning the trait theory, Gordon (1983) refers to Stodgill's work (1974) and to Ghiselli's work (1971) in concluding that the traits associated with leadership in one situation do not predict leadership in other situations; she says "no clear pattern of which traits make an effective leader has emerged" (p. 394). Andriessen and Drenth (1984) agree with Gordon, when they say that interest in the trait approach to leadership has waned since the 1950's, because few traits could be found that distinguish between "good and bad leaders, or between leaders and followers" (p. 487).

Gordon (1987), as opposed to some of theorists reviewed here, sees the charismatic personality as important to Transformational leadership (p. 395). Therefore, Gordon sees the study of Transformational leadership as a return to trait theory. I will address this charisma in leadership below. In discussing Fiedler's Contingency Theory (effective leadership style is dependent upon the situation), Gordon refers to criticisms by Barrow (1977), by Singh (1983), and by Hosking and Schriesheim (1978). A major concern is that the theory fails to predict effective leadership. Gordon (p. 405-406) suggests that incorporating more situational variables might improve predictability. The behavioral view concentrates on a given leader's actions; early studies of behavior evaluated whether a leader was basically authoritarian, democratic or laissez-faire in dealing with subordinates, while later studies looked at leadership behaviors as production-oriented (getting the task done) versus employee-oriented (concern for people). The terms, production-oriented and employee-oriented are often connected with studies in the 1940's at the University of Michigan; at the 
same time the Ohio State Studies through the Leader Behavior Description Questionnaire developed parallel terms, consideration (a leader's behavior demonstrating care for followers) and initiating structure (a leader's behavior in delineating the relationship between leaders and workers). According to Goldhaber (1990), Blake and Mouton based their two-dimensional grid theory on these university studies; Blake and Mouton contrast leader concern for people with leader concern for production. The attributional view is that leadership exists only as an individual's perception, not as an objective factor of a situation. Bass (1981, p. 36) says of the attributional theory:

"For Calder (1977), leadership changes from a scientific concept to a study of the social reality of members and observers. Leadership is seen as a study in how the term is used, when it is used, and assumptions about the development and nature of leadership. Ratings by observers and subordinates are biased by their own individual social realities (Mitchell, Larson \& Green, 1977; H. M. Weiss, 1977), which accounts for the low correlations often found between supervisor, peer, and subordinate ratings of the same leaders (Ilgen \& Fujii, 1976; T. R. Mitchell, 1970a; Bernardin \& Alrares, 1975) as well as for the confounding of evaluations of subordinate performance and leader's behavior (Rush, Thomas \& Lord, 1977)."

The operant conditioning model studies the repeated interaction of leader and subordinates as they reinforce, punish, or extinguish the behavior of one another.

As noted above, some see the charismatic personality as important to Transformational leadership. "Charisma is leadership by virtue of personality" (Goldhaber, 1990, p. 99). Regarding charisma, Bennis and Nanus (1985, p. 223-224) have concluded that charisma is the result of effective leadership, not the other way around:

"Our leaders were all "too human"; they were short and tall, articulate and inarticulate, dressed for success and dressed for failure, and there was virtually nothing in terms of physical appearance, personality, or style that set them apart from their followers."

On the other hand, Bass (1985b) writes,

"Charismatic leaders are transformational in that they, themselves, have much to do with the further arousal and articulation of such feelings of need among followers. Charismatic leaders have insight into the needs, values, and hopes of their followers. They have the ability to build on these needs, values, and hopes through dramatic and persuasive words and actions...(p. 46)"

and "A charismatic personality makes success as a leader more likely, but it is not essential 
for such success (p. 49)." Bass (1985b) had 104 military officers complete a Leadership Questionnaire on their immediate supervisors; a principal components factor analysis supported the relationship between what he calls charisma and Transformational leadership. In his study the correlation between charisma and subordinate satisfaction was .91 and between charisma and perceived leader effectiveness was .85 . As charisma is further studied and defined, the argument over whether the charismatic personality is or is not important to Transformational leadership may subside.

If we look at the Charisma Theory apart from Transformationalism, it may be summarized by the following four propositions (Goldhaber, 1990, p. 103):

1. The amount and type of a leader's charisma is the result of the perceptions of the people who assess that charisma.

2. Perceptions of a leader's charisma will vary according to time, place, and other factors that affect that perception.

3. Leaders perceived to have the greatest amount of the right kind of charisma will be most effective.

4. Perceptions of charisma can be measured and enhanced, primarily through adept use of the media.

The possible link between charisma and Transformational leadership is beyond the scope of this present study. Future studies will have to take into account the growing evidence that charisma is an important element of leadership.

Other theorists seem to stress not the individual traits, which were studied in the past, but the interactive roles or the interactional dimensions. I tend to subscribe to this majority position.

No one leadership theory has emerged as dominant. Burns (1978, p. 2) says leadership is "one of the most observed and least understood phenomena on earth." Hollander (1985) quotes Sims (1977) as saying: "Leadership is perhaps the most researched and least understood area of organizational behavior" (p. 488). Andriessen and Drenth (1984) state that it is unclear what the relevant dependent variables are in leadership research. They fault the lines of research for staying with correlational studies, which fail to get at causal relations and for using simplistic theoretical models in light of the complexity of the leader-follower interaction (pp. 482-483). 


\section{PRINCIPAL LITERATURE AND DEFINITIONS}

Theoretical statements on leadership found in psychological material seem to fit with Biblical orientations to leadership. This fit led to this line of inquiry in the hope that pastors and parishioners might gain more mutually beneficial relationships.

What does leadership mean? In the Bible the Old Testament Hebrew words and the New Testament Greek words for "lead," "leader," and "leadership" give the picture of "standing before" (perhaps meaning that the leader had a group's attention in order to share his or her vision), and give the picture of "going before" (perhaps meaning that the leader was modeling for the group, as well as, putting himself or herself on the line for the common purpose). Our English words for "lead," "leader," and "leadership" seem to derive from similar backgrounds.

\section{Transformational And Transactional Leadership}

Transformational leaders concern themselves with those things necessary to reach potential, while Transactional leaders concern themselves with what is necessary to maintain the status quo. Burns (1978) sees the two leadership styles on opposite ends of a continuum, while Bass (1985) sees any given leader as exhibiting a variety of patterns of Transformational and Transactional leadership.

In order to clarify Transformational leadership, it is often contrasted with Transactional leadership; this is seen in the literature as described below. On the other hand, Brown (1987) refers to the work of Avolio and Bass (1985) when she says, "The most successful transformational leaders are supported by their ability to manage the day-to-day events that implement their agendas (i.e., transact with subordinates)" (pp. 29-30).

In the late 1970's, Zaleznik $(1977,1983)$ and Burns (1978) began to differentiate between leadership and management "with respect to role, process, function, and theories (Gibbons, 1986, p. 11)." Burns (1978), in a historical survey, contends that political leaders who have made a significant impact have been Transformational. Transformational leaders do more than maintain the status quo--they help their followers reach their potential (Bass, 1985b). Harris (1985) sees the Transformational manager as the one able to lead into the future. A Transactional leader, on the other hand, directs his or her attention to maintaining the status quo; avoids risks; holds to current margins and levels of activity; goes by the old maxim: "if it ain't broke, don't fix it." A Transactional leader seeks to keep his or her 
followers and organization happy by meeting expressed needs; he or she interacts with them economically (exchanging money for effort), politically (exchanging jobs for votes), or psychologically (exchanging nurturance for respect). While not neglecting expressed needs, the Transformational leader seeks to identify higher (self-actualizing) needs and to mobilize his or her followers and organization to meet those needs. A Transformational leader is interested in improving product, morale, methods, and margins; he or she is inquisitiveasking: "what if?," innovative-desiring to be on the cutting edge, and willing to take risks. $\mathrm{He}$ or she seeks to motivate, engage, and stimulate a follower to give of himself or herself to meet the new goals. Innovation and change are often needed for the followers and organization to reach their potential. Bass (1985b, p. 20) paraphrases William F. Buckley as saying that the Transformational leader is one who "crystallizes' what it is that people desire, 'illuminates' the rightness of that desire, and coordinates its achievement." Tichy and Ulrich (1984) summarize the expectations of Transformational leadership:

"What is required of this kind of leader is an ability to help the organization to develop a vision of what it can be, to mobilize the organization to accept and work toward achieving the new vision, and to institutionalize the changes that must last over time."

Bass (1985a, p. 31) says transformations can be achieved by:

1. Raising our level of consciousness about the importance and value of designated outcomes and ways of reaching these outcomes.

2. Getting us to transcend our own self-interests for the sake of the team, organization, or larger polity.

3. Raising our need level on Abraham Maslow's hierarchy from, say, the need for security to the need for recognition, or expanding our portfolio of needs by, for example, adding the need for self-actualization to the need for recognition.

Gordon (1987) says that Transformational leaders change organizations in four ways:

"They identify the triggers for a major change. They create a vision of the change. They become personally committed to the change and obtain subordinates' commitment as well. Finally, they institute change by managing the organization's structure, management processes, culture, and human resources" (p. 702).

Levy and Merry (1986) list these characteristics of Transforming leaders from Deal and Kennedy's (1982) work:

"They are highly visible, credible, and consistent in support of the values they espouse. 
They are masters of communication.

They use symbolic actions such as rites, rituals, and ceremonies to reinforce their values.

They motivate employees by providing positive reinforcement.

They provide a lasting human climate within the system.

They know how to succeed and to make change attainable andpart of human capacity.

They provide positive role models for workers to follow.

They set high standards of performance.

They encourage creativity, innovation, and trial and error" (p. 53).

Transformational leaders are interested in 'second order change.' This term refers to major or fundamental shifts in attitudes, beliefs, needs, and values and dramatic increases in output, productivity, and quality (Bass, 1985b; Gibbons, 1986; Brown, 1987). This fits with my own working definition of leadership. On the other hand, Transactional leaders are interested in 'first order change.' In Contrast to second order change, first order change is defined as incremental, changes of degree, minor or routine shifts within the same context or framework. (Bass, 1985, pp. 3-5; Brown, 1987). In either case, the changes may be in attitudes, programs, and/or organization.

Tichy and Devanna (1986a) say that Transactional leaders change little, manage what they find, and leave things much as they find them when they move on, whereas Transformational leadership is about "change, innovation, and entrepreneurship...It's a leadership process that is systematic, consisting of purposeful and organized searches for changes, systematic analysis, and the capacity to move resources from areas of lesser to greater productivity (p. 27)." Tichy and Devanna differentiate Transformational leaders from Transactional managers:

They identify themselves as change agents.

They are courageous individuals (prudent risk takers).

They believe in people (ultimately work toward the empowermentof others).

They are value-driven (able to articulate a set of core valuesto which they were dedicated).

They are life-long learners (from failures as well as successes).

They have the ability to deal with complexity, ambiguity, and uncertainty.

They are visionaries (able to dream and to translate those dreams so that others could share them) (pp. 30ff). 
Some of the distinctions that Harris (1985) makes between what he calls the "traditional manager" and the "transformational manager" will help to clarify some of the differences between the Transactional and the Transformational leader: slow to act versus forcefully acts, past-oriented versus future-oriented, short-term oriented versus long-term oriented, plays it safe versus on the cutting edge, conformity versus initiative, pragmatic versus conceptualizer, and concern for average performance versus sets high personal and professional standards for self and others (p. 21).

Based on interviews, Gibbons (1985, p. 198) says of the Transformational leaders in her study that they

"approached and engaged in their development in a more conscious, deliberate, explicit way than have the others. They apply the same desire and eagerness, and the same standards of excellence to themselves as they do to other aspects of their life and work. They are self-reflexive, in that they create or define learning opportunities for themselves, then reflect on their experience and integrate it. They are also willing to take on and confront the pain which this sort of self-examination entails. They are, by their own descriptions, courageous risk-takers who are willing to take a stand for what they believe is right-including themselves!"

As mentioned above, for clarity's sake Transformational leadership is often defined in contrast with Transactional leadership. The contrasts found in the literature reviewed above were the basis of the coding manual for an earlier study by the present author (Bray, 1989).

Increased effectiveness and satisfaction are associated with Transformational leaders according to Bass's (1985b) research. In Stogdill (1981, p. 10) Bass referred to his earlier work (1960) in defining effective leadership in contrast to attempted leadership: attempted leadership is effort to change the behavior of others; successful leadership is when others actually change; and effective leadership is when others are rewarded or reinforced for their change. Bass's model (1985, p. 22) measures leadership effectiveness by comparing subordinate effort under Transactional leadership and subordinate effort under Transformational leadership. In a study of military officers, junior officers reported on Bass's "Scale of Extra Effort" that they were motivated beyond original expectations more by Transformational leaders than by Transactional leaders (1985b, pp. 213-214). Bass (1985b) also reports a number of biographical studies of professional, educational administrators and industrial managers where specific aspects of extra effort and effectiveness were found to be related to Transformational leaders (p. 219). Bass (1985b) conducted two studies on Army officers and one on business managers to measure subordinates' extra effort and perceptions of 
effectiveness; when the Transformational factor scores were added to a leader's transactional factor scores, both the perception of extra effort and of effectiveness were significantly increased. Deluga (1988) says "(T)ransformational leadership was found to be more closely associated with leader effectiveness and employee satisfaction than was transactional leadership."(p. 463).

What are some other criteria of leader effectiveness? Bass (1981) says:

"Hunt, Osborn, and Schriesheim (1977) noted in review of eighty-nine studies published between 1970 and 1975 that 61 percent used only a single criterion, with some emphasis on performance (43 percent). However, a greater use of multiple criteria was noted in field studies. Most (81 percent) used criteria obtained from a different informational source than the predictors.

"Studies have been conducted on the response of follower be liefs, satisfaction, and behavior, as well as group productivity, drive, and cohesiveness to leader behavior. However, certain variables such as group productivity and follower satisfaction have been overemphasized at the expense of other variables. For instance, group drive, which presumably should be affected by transformational leadership, in particular, has been widely neglected as a variable in group performance" (p. 612).

Bass (1981, p. 613) concludes that future research on leadership should incorporate measures of group performance. Let me note that although the present study is concerned with leadership effectiveness, this study is not attempting to measure leadership effectiveness. A study on church leadership effectiveness might follow up on the analysis of church organizational effectiveness of Pargament et al (1987), who say, "Effective organizations have been described as capable of maintaining themselves as viable systems, facilitative of the relationships among members, and helpful to the personal development of their members" (p. 274). In a comparison of conservative and mainline Lutheran churches they used three types of measures to study the strengths and weaknesses: congregational climate, congregation satisfaction, and member commitment and involvement.

Current research and discussion on Transformational leadership focus on several dimensions: some examine leadership effectiveness of Transformational vs. Transactional leaders; others investigate worker satisfaction with Transformational leaders vs. Transactional leaders; others search for the environmental, experiential, or educational determinants of Transformational behavior with a purpose of training leaders to be more Transformational; another carried on a qualitative case study; another has looked for behavioral competencies; and still others look to more fully distinguish Transformational from Transactional concepts 
(Bass, 1985b, Brown, 1987, Burns, 1978, Deluga, 1978, Freiberg, 1987, Gibbons, 1986, Singer, 1985, Singer \& Singer, 1986, Tichy \& Devanna, 1986a, 1986b). These studies are usually located in business, military, or political settings. The present study breaks new ground by exploring religious groups.

Most Transformational leadership studies to date have been descriptive rather than empirical. As Brown (1986) has said, these studies are "exploratory in nature to develop theory rather than testing theory through controlled measurement and sampling" (pp. 13-4).

Bass (1985b) says,

"If transformational leadership is as important to productive and service organizations as it is to political action, society, and history, then we will need to learn how to develop in managers the sensitivity and interpersonal competence required for them to function as transformational leaders" (pp. 31-32).

Gibbons (1986) agrees with Bass when she writes, "The existing body of knowledge on transformational leaders and leadership in organizations consists primarily of the work done by Bass (1985b), Bennis and Nanus (1985), Burns (1978), Levinson and Rosenthal (1984), Maccoby (1981), and Zaleznik (1977, 1983, 1984)" (p. 6). Most of these studies are experiential and descriptive, while Bass's (1985b) study is empirical. The present study seeks to expand the small empirical base.

To better understand Transformationalism one might ask, what kind of organizations are Transformational leaders working toward? According to Brown (1987, pp. 53ff), Kiefer and Senge (1984) have identified what they have termed the metanoic organization. Metanoia is a Greek word made up from "meta," a preposition, which when used with words regarding mental activity indicates a change in the meaning and from "noia," a noun, which means mind. Thus, the word metanoia means "change of mind" and when used in a religious context, it is usually translated as "repentance" (Brown, 1985, p. 357). Brown (1987) describes such an organization:

"There are several basic cultural assumptions of these organizations: people are good, honest, and trustworthy; people are purposeful; everyone has a unique contribution to make; and complex problems require local solutions (Kiefer and Senge, 1984). It takes a special quality of leadership to bring a metanoic organization into being: one that stems from the leader's soul rather than behavior (Kiefer, 1986). The abilities these leaders share transcend personality or style which have been the focus of many previous leadership theories (Senge, 1980). Kiefer and Senge (1984) identified five dimensions used to shape a coherent organizational philosophy which 
can lead to extraordinary influence on the world in which the entity exists. The dimensions are: deep sense of vision and purposefulness, alignment around that vision, empowerment of people, structural integrity, and balance of reason and intuition. Kiefer (1986) regrouped the basic ideas of the dimensions into three functions of leadership: custodian or steward of the vision, empowerment and coaching of others to create what they want, and creation of structure. These functions go beyond personal mastery to organizational mastery which is the ability to sustain the vision in unity with others" (pp.53-54).

\title{
Leadership In The Church
}

We now turn our attention to the leadership concerns of the church. Before examining the Biblical literature, I will survey some issues currently being raised. Howard (1984) says,

\begin{abstract}
"Schaller (1983), Schuller (1974), and Engstrom (1976) indicated that the Church is one organization that has often been less than effective as a result of deficient leadership. They state, however, that during the past twenty years there has been a movement away from uncontested pastoral leadership. Traditionally, church adherents feared interrupting one of 'God's choice servants.' Since ministers are involved in a spiritual work with emphasis on the supernatural and invisible, they and their parishioners tend to feel that leadership is something that is intangible (Schaller, 1983). Added to this is the fact that many ministers are not trained in leadership theory and as a consequence have few leadership skills to help them in their task (Engstrom, 1976). 'They have been led to believe in the great man theory that individuals are born leaders and that leadership is not something that is developed' (Burlingame, 1973, p. 45). Identifying leadership qualities necessary for meeting ministerial responsibilities is a great concern for religious organizations and their educational institutions. Of equal concern is the identification of the expectations that churches have in regard to the leadership they feel is needed to maximize the potential for growth of their church" (p. 4).
\end{abstract}

At one time the pastor was the most highly educated member of the church and community; today, others may be equally as educated. At one time the pastor and parishioners shared a common reverence for the Bible and the supremacy of God; today, pastors can no longer take this commonality for granted. Robinson (Hybels, Briscoe, \& Robinson, 1989) says:

"A century ago, the pastor was looked to as the person of wisdom and integrity in the community. Authority lay in the office of pastor. The minister was the parson, often the best educated person in town, and the one to whom people looked for help in interpreting the outside world. He had the unique opportunity to read and study, and often was the principal voice in deciding how the community should react in any moral or religious situation" (his emphasis; p. 19).

In a similar vein, Hybels (Hybels et al, 1989) says: 
"There was a time when your word was a guarantee, when marriage was permanent, when ethics were assumed. Not so very long ago, heaven and hell were unquestioned, and caring for the poor was an obvious part of what it meant to be a decent person. Conspicuous consumption was frowned upon because it was conspicuous. The label "self-centered" was to be avoided at all costs, because it said something horrendous about your character.

"Today, all that has changed. Not only is it different, but people can hardly remember what the former days were like" (p. 28).

Thus, the consensus is that today's pastors are leading from a weaker position than they once enjoyed. If this consensus is accurate, then the Transformational changes that they seek will be even more difficult to accomplish than in past eras. Brown (1987) says real Transformational changes are usually possible only in times of crisis; if this is true, then a church may find it difficult to accept a pastor's recommendation for radical change, when church volunteers are in place for existing programs and offerings are meeting budgetary needs (p. 11). A pastor, as a Transformational leader, must, then, create a sense of urgency. Tichy and Devanna (1986b) give Iacocca at Chrysler as an example in this regard. Today, leadership studies are taking culture seriously. Brown (1987) says, Schein (1985) has defined culture as "basic assumptions and beliefs shared by members of an organization which operates unconsciously and shapes the organization's views of itself and its environment" (p. 8). Because church culture through Scripture and other traditions is so ingrained in the typical parishioner, a pastor attempting Transformation is more likely than a business or political leader to encounter resistance. At some point, tension reduces effectiveness and, perhaps, reduces pastoral tenure.

\section{Biblical Concepts of Church Leadership}

What are the Biblical concepts of church leadership? The author has observed that theoretical statements on leadership found in psychological material seem to fit with Biblical orientations to leadership. The nature and functions of the church suggest that leadership within the church would ideally be Transformational. The Apostle Paul commands the church at Rome to be "transformed" (Romans 12:2); the Greek word, "metamorphoo," used here gives us the English word "metamorphosis." Paul is writing to those who are already part of a local church; the context is conformity to a way of planning or thinking--"Do not conform any longer to the pattern of this world, but be transformed..." While some are calling for Transformational leaders to meet the challenges of the economic and social environment of today's post-industrial era, pastors may tend to be Transformational because of Biblical imperatives. The Bible itself seems to stress among other Transformational 
aspects of pastoral leadership these three: modeling-"(S)et an example for the believers in speech, in life, in love, in faith, and in purity" (II Timothy 4:12), perseverance-"Until I come, devote yourself...Do not neglect...Be diligent in these matters; give yourself wholly to them...Persevere..." (II Timothy 4:13- 16), and involvement in a breadth of ministry (versus a limited, chaplain-like involvement)-"(D)irect the affairs of the church..." (I Timothy 5:17) and "Preach the Word...correct, rebuke, encourage...do the work of an evangelist, discharge all the duties of your ministry..." (II Timothy 4:2-5). These distinctions were found by the author in a study of the Pastoral Epistles. These letters are commonly regarded within the Conservative Baptist denomination as outlining the expectations (requirements) of church leaders.

In a verse by verse analysis of the above epistles several additional categories were found: title or position, personal relationships, needs to be met, things to avoid, and general qualifications. No justification was found to consider any of these additional categories as Transformational or Transactional concerns. Therefore, they are not considered in this study.

Bandura's (1986) analysis of motivation and learning lends credence to the Biblical priority of Modeling; as well, Deal and Kennedy (1982) according to Levy and Merry (1986) referred to "positive role models" in the list mentioned earlier. Bass (1985a) says, "The transformational leader will consciously or unconsciously serve as a role model for subordinates" (p. 35). Kouzes and Posner (1988) say, "The leader must model the way." (their emphasis, p. 11) and "Being a role model means paying attention to what you believe is important. It means showing others through your behavior that you live by your values" (p. 12). They quote Donald Kennedy, President of Stanford University: "The leader's job is to energetically mirror back to the institution how it best thinks of itself" (p. 190). Friedman (1986) thinks Modeling is so central to leadership that he says leadership is not a matter of how a leader deals with followers, but a matter of a leader's own "self- differentation" affecting his or her followers. Transformational change is rewarded only after an extended time, whereas Transactional change may be rewarded relatively quickly. Because followers do not see the rewards of Transformational change as quickly as they do a Transactional change, the need for greater Perseverance in a Transformational leader can be seen intuitively. Burns (1978), as summarized by Gibbons (1986), seems to support this assumption when he says that "leaders must be willing to make enemies, that they must accept and embody conflict, and be willing and able to be unloved" (p. 20). Harris (1985) seems to support the intuition when he notes the long-term orientation of the Transformational leader (mentioned earlier). Harris also notes that as a "conceptualizer" a Transforma- 
tional leader "links together pieces and parts into a whole" (p. 21); such a leader must attend to the whole, to the Breadth of ministry concerns. Likewise, Bennis and Nanus (1985) characterize the leader as one who becomes acquainted with and interested in every aspect of the organization. 


\section{ASSUMPTIONS AND HYPOTHESES}

Do parishioners and pastors have different views regarding these Transformational/Transactional concepts? An earlier study (Bray, 1989) demonstrated that they do. If they have different views, could these differences have a significant impact on pastoral tenure (i.e., does tension result and cause a pastor to be fired or to resign under pressure?) and other aspects of pastor-parishioner relationship? For example, Christian leaders have been voicing concern about the brevity of pastorates since I entered the ministry in 1975. George (1987) says despite the tendency for short pastorates, "...a pastor's most effective period of ministry comes after the sixth year, according to many church observers." On April 28, 1988 I spoke with Dwane Shockly, a leader in my denomination (the Conservative Baptists of America); he says the average pastorate in our sister denominations in the U.S. is approximately three years and in our denomination it is only slightly longer. That same day I talked to Vince Rutherford of the Charles E. Fuller Institute of Church Growth and Evangelism. He says Baptist pastors stay an average of two years in a church and this despite the Institute's conviction that a pastor becomes most effective in six to ten years.

Three basic assumptions of my earlier research (Bray, 1989) were: 1) that there is a difference between pastors and parishioners in their perceptions of Transformational and Transactional leadership positions; 2 ) that this difference leads to friction (tension) between parishioners and pastors; and 3) that this friction (tension) causes pastors to have brief tenures. In the earlier study (Bray, 1989) only the first assumption was tested. Significant differences in the hypothesized direction that pastors are more Transformational than parishioners were found for the basic Transformational/Transactional distinction and for the Transformational sub-dimensions of Perseverance and Breadth of Involvement. One element (a love factor which is described below) of the Modeling sub-dimension was identified as particularly important to the parishioners (i.e., listed by the parishioners more than all other elements combined on the relevant open-ended questions).

The present study also assumed that:

1) pastors are more Transformational than parishioners;

2) these differences produce tensions (conflicts) in pastor/parishioner relationships; and

3) this tension causes pastors to have brief tenures.

This third assumption is not directly investigated in this present study. 
Three hypotheses were formulated:

$\mathrm{H}_{1}$ : Pastors will respond more Transformationally relative to parishioners regarding the basic leadership distinction;

$\mathrm{H}_{2}$ : Pastors will respond more Transformationally relative to parishioners on the three Transformational sub-dimensions; and

$\mathrm{H}_{3}$ : Parishioners more frequently than pastors would relate Transactional rather than Transformational behaviors to reduced tensions.

To test the first hypothesis research participants were asked to describe how they felt a "successful pastor" should behave as a leader and, then, answer the same questions for an "unsuccessful pastor." It was thought that richer information would be gained by asking for both the "successful pastor" and the "unsuccessful pastor" behavior. This part of the investigation utilized a Likert-scale. This basic Transformational/Transactional distinction was addressed both in section one of Part Two of the questionnaire and by comparing the pastors' responses to the parishioners' responses on the "successful pastor" in Part One of the questionnaire. In the earlier study, a significant difference between pastors and parishioners was found regarding this basic Transformational/Transactional distinction. In this present study, two new approaches were utilized to retest the hypothesis.

The sub-dimensions of Transformationalism (Modeling, Perseverance, and Breadth of Involvement) developed for this study were also investigated to test the second hypothesis. In the earlier study, a significant difference between pastors and parishioners was found regarding two of the three sub-dimensions. In this present study, a new approach was utilized to retest the hypothesis.

An open-ended question, concerning tensions between pastors and parishioners regarding the pastoral leadership role was added at the end of the questionnaire to test the third hypothesis. It was thought that parishioners more often than pastors would see pastors' emphasis on Transformational concerns rather than the parishioner's Transactional needs resulting in tension. Responses elsewhere in the questionnaire are compared to the responses to the open-ended question in a qualitative way in order to begin to establish a link between pastor/parishioner differences and tension; this comparison was pursued without hypothesis.

Transformational leadership theory in general would predict that pastors, if they are more Transformational than parishioners, would respond more Transformationally than 
parishioners on issues regarding the demonstration of love, compassion, and concern for others. That is, pastors should expect that "successful pastors" will freely express in these areas, while parishioners should expect them to modestly express and visa versa for "unsuccessful pastors." This did not prove to be the case in the earlier (Bray, 1989) study, based on information gathered by open-ended questions. On the one hand, consistent with Transformational theory one could assume that pastors would be more Transformational than parishioners. On the other hand, the church gives a central position to the teaching on love has and parishioners gave considerably greater emphasis to this factor in the earlier study. Therefore, I made no hypothesis regarding a possible significant difference on this variable.

This present study has several goals. First, it will replicate and extend the previous study. Second, the modeling sub-dimension of the Transformational/Transactional concept will receive further study. In the previous study, using an open-ended questionnaire, one aspect of modeling provided more of the responses judged to be Transformational by the coders than the rest of the modeling aspects combined. This modeling sub-dimension, which was labeled "the love factor," included statements regarding pastors expressing love, compassion, concern, etc. to the parishioners. Parishioners gave considerably greater emphasis to this factor than pastors. In this present study, participants had opportunity to respond directly to an expanded assessment of this factor. Third, the questionnaire format, through Principal Components Analysis (albeit preliminary, because of the small $n$ ), was designed to demonstrate (cluster) more specifically where the differences occur along Transformational/Transactional lines between pastors and parishioners. These differences were explored utilizing descriptions of "successful pastors" and descriptions of "unsuccessful pastors." Fourth, the study was an attempt to take a preliminary look at whether the leadership perspective differences translate into increased tension between pastors and parishioners. Finally, the more general theory of Transformational/Transactional leadership was to be further explicated by extending it into a religious setting. 


\section{METHOD}

\section{Introduction}

There is a gap between a theoretically ideal pastoral term (ten years) and the more frequently observed term of less than three years. This study is part of a series of studies undertaken to determine 1) whether pastors and parishioners differ in their expectations of church leadership along Transformational and Transactional lines, 2) whether that difference is associated with tension in pastor/parishioner relations, and 3) whether that tension causes pastors to have brief tenures. This research operationalizes and extends the Transformational and Transactional leadership perspectives into a religious setting. A review of the social science literature, as well as, the Biblical literature suggested the particular importance of the Transformational leader providing a Model, being involved in a wide Breadth of interests, and Persevering. The Transactional leader, on the other hand, is less concerned about providing an example, is interested only in a few specific areas, and is likely to conform.

The development of the questionnaire, participants, procedure, and coding are discussed below. The research comprised four steps: 1) gathering data through a Likert-type questionnaire; 2) performing the statistical analyses (Principal Component Analyses [PCA's], Multivariate Analyses of Variance [MANOVAs], and $t$-tests) on Parts one and two of the questionnaire; 3) developing the PCA scale and validating the construct; and 4) through use of independent raters, comparing (by $t$ - tests) the responses to the open-ended question on tension to the PCA clusters from Part one. This latter comparison was an initial attempt to look for possible connections between leadership variables and tensions or conflicts research participants mentioned in the open-ended question.

\section{Development of the Questionnaire}

In order to investigate the Transformational hypotheses, a three-part questionnaire was utilized (see Appendix 1). Part One was designed to further investigate the Transformational/Transactional difference between pastors and parishioners found in the earlier study. Part One has two sections with 46 items in each; section one has 46 items to be considered in reference to a "successful pastor" and section two has the same 46 items to be considered in reference to an "unsuccessful pastor." Part Two of the questionnaire has four sections: section one has nine items assessing the basic Transformational/Transactional distinction; section two has seven items on the Transformational sub- dimension of Modeling; section 
three is a single question on the Transformational sub-dimension of Breadth of Involvement; and section four is a single question on the Transformational sub-dimension of Perseverance. Part Three of the questionnaire is a single open-ended question on Tension.

Part One of the questionnaire, which includes 46 items, was derived from material in the coding manual (see Appendix 2) on Transformational/Transactional distinctions utilized in the earlier study (Bray, 1989). As mentioned in the literature review, Transformational leadership is often defined and explained in contrast to Transactional leadership. A number of contrasts were utilized in the coding manual (see Appendix 2) for the earlier study and formed the basis of the statements (pairs of contrasting statements; see Appendix 3) in the first part of the present questionnaire. These statements were originally part of 35 pairs (70 contrasting statements; see Appendix 2) of contrasting characterizations or statements (Transformational vs. Transactional statements). In the earlier study, these statements were used as part of a coding manual to determine whether questionnaire responses to open-ended questions were Transformational, Transactional, or Other. It was assumed that the coding manual for the earlier study contained more items than would be reasonable for the questionnaire for this present study; including all the previous items would have made the questionnaire too lengthy. For this present study the number of items that had made up the earlier coding manual were first reduced by 28 items (or by 14 Transformational items and 14 Transactional items). As will be discussed below, after the number was reduced, two items labeled the "Love Factor" from the previous coding manual were then expanded to six items-making a total of 46 items (23 pairs of contrasting statements; see Appendix 3). For the actual questionnaire for this present study the 46 items appeared in random order in order to reduce any systematic response bias.

Two expert coders, both trained in Transformational/Transactional distinctions for the earlier study, independently rated items for inclusion or exclusion as outlined above. Those items judged with 100 percent agreement as similar to other scale items were deleted. Those items judged with 100 percent agreement as lacking clarity in making coding decisions in the earlier study (Bray, 1989) were also deleted. The contrasting leadership perspectives are written here (in Part One of the Questionnaire) as short statements; care was taken to avoid an undue negative connotation in the statements.

Each of the 46 statements in Part One called for a Likert-type response on a five point scale (' $\mathrm{A}$ ' indicates 'strong importance', ' $\mathrm{B}$ ' indicates 'mild importance', ' $\mathrm{C}$ ' indicates 'undecided', ' $D$ ' indicates 'mild unimportance', or ' $E$ ' indicates 'strong unimportance'. 
Participants were first asked to respond to forty-six (46) statements while being instructed to describe 'a successful pastor' and, second, they were asked to respond to the same statements while keeping 'an unsuccessful pastor' in mind. The 46 statements in Part One of the questionnaire include 23 Transformational statements and 23 Transactional statements that may be descriptive of pastors as leaders (see Appendix 3). In both sections of Part One of the questionnaire the scoring for the 23 Transformational statements was 5 for ' $\mathrm{A}$ ', 4 for ' $B$ ', 3 for ' $C$ ', 2 for ' $D$ ', and 1 for ' $E$ ' responses, while the scoring for the 23 Transactional statements was 1 for ' $A$ ', 2 for ' $B$ ', 3 for ' $C$ ', 4 for ' $D$ ', and 5 for ' $E$ ' responses; thus, the higher scores in any case reflected a more Transformational versus Transactional response, while the lower scores in any case reflected a more Transactional versus Transformational response.

From the coding manual for the earlier study (Bray, 1989) one pair of contrasts, which was later called "the love factor," seemed to warranted further study. In the Coding Manual (see Appendix 2) for the earlier study this item (pair of contrasting statements) read as follows: "concerned beyond expressed needs (love, compassion, and concern for others) vs. addresses only expressed needs." This item has been expanded in the present study to six statements:

"fairly free to express love,"

"fairly modest about expressing love,"

"fairly free to express compassion,"

"fairly modest about expressing compassion,"

"fairly free to express concern for you," and

"fairly modest about expressing concern for you."

These 6 items are included in the 46 items discussed above; thus, both section one, the "successful pastor," and section two, the "unsuccessful pastor, of Part One of the questionnaire ask for responses to 46 items and individually form the basis for two PCAs.

Part Two of the questionnaire has four sections; in each case the several questions covering a particular concept in the previous study were organized into one section for this study. For the first section (items 121-129 on the answer sheet) and the second section (items 181- 187 on the answer sheet), participants were asked to respond to statements that were judged by the coders of the previous study as Transformational. The first section (items 121-129 on the answer sheet) is directed toward the basic Transformational/Transactional concept, while the second section (items 181-187 on the answer sheet) is directed toward 
the Transformational sub-dimension of Modeling; for items 121- 129 one such statement was "his presenting a vision" and for items 181-187 one such statement was "his involvement in the lives of others." Both sections ask participants to respond to a each concept by choosing from a Likert-type five-point scale: " $\mathrm{A}$ " through " $\mathrm{E}$ " for "strongly agree," "mildly agree," "neutral," "mildly disagree," or "strongly disagree." The scoring for the items in these two sections was 5 for " $A$," 4 for " $B$," 3 for " $C$," 2 for " $D$," and 1 for " $E$ " responses; thus, higher scores in any case reflected a more Transformational versus Transactional response, while lower scores in any case reflected a more Transactional versus Transformational response.

Sections three and four of Part Two of the questionnaire look at two other Transformational sub-dimensions: Breadth of Involvement and Perseverance. Section three (item 200 on the answer sheet) reads:

Churches have expectations of their ministers; sometimes these expectations may be found in written job descriptions. Some ministers provide leadership beyond the job description areas and others provide leadership only within the job description areas. Do you agree with a pastor providing leadership beyond the job description areas (please fill in $A, B, C, D$, or $E$ )?

Section four (item 201 on the answer sheet) reads:

Suppose there are differences between the pastor and parishioners. He has a choice between accepting their position as final or using his leadership skills to attempt to change their minds. In this situation do you agree with a minister using leadership skills to change their minds (please fill in $\mathrm{A}, \mathrm{B}, \mathrm{C}, \mathrm{D}$, or $\mathrm{E}$ )?

Both section three on Breadth of Involvement and section four on Perseverance ask participants to respond to a single question on a five-point scale: " $\mathrm{A}$ " through " $\mathrm{E}$ " for "strongly agree," "mildly agree," "neutral," "mildly disagree," or "strongly disagree." The scoring for the items in these two sections was 5 for " $\mathrm{A}$," 4 for " $\mathrm{B}$, " 3 for " $\mathrm{C}$," 2 for " $\mathrm{D}$," and 1 for " $E$ "responses; thus, higher scores in any case reflected a more Transformational versus Transactional response, while lower scores in any case reflected a more Transactional versus Transformational response.

Part Three of the questionnaire is an open-ended question that attempts to identify areas of tension or conflict between pastors and parishioners; the question reads:

During the course of a pastorate sometimes tensions or conflicts arise over leadership issues. With this in mind, please complete the following: Parishioners and pastors would have less tension (conflict), if pastors (in their leadership role) 
would concentrate less on

and concentrate more on

\section{Participants}

The participants were 44 ministers and 42 parishioners from Conservative Baptist churches. The ministers were gathered for a Northeast (this area includes the New England states, New York, Pennsylvania, and New Jersey) regional associational meeting; volunteers were requested through a public announcement at the meeting. The parishioners were members of two churches in Rhode Island, and one church each in Connecticut and Massachusetts; parishioners were sought from mid-week services. Participation was voluntary. The churches differed from one another in some ways: one was a large suburban church, which had grown steadily under a former pastor and was continuing to grow under a pastor new to the church; another was a large suburban church, which had grown rapidly in recent years; a third was a rural church, which has had the same pastor for over 35 years; and the fourth was an inner-city church, which has experienced decline for several years. All ministers are males. The parishioners included 20 males and 22 females; the breakdown reflected the attendance at the meetings in the experimenter's judgment. All participants signed an informed consent form (see Appendix 4). This was a non-random sample (sample of convenience).

To improve the subject/item ratio (i.e., provide factor stability for the Principal Component Analyses [PCAs]) ninety six (96) URI students completed Part One of the questionnaire; their responses were to be taken together with those from the pastors and parishioners and to be utilized to identify the PCA factors. Unfortunately, PCA's with the student data provided a different factor structure for both the "successful pastor" and the "unsuccessful pastor" sections than did PCAs utilizing only the pastor and parishioner data; thus, the student generated data were not further analyzed.

\section{Procedure}

Subjects were told that the purpose of the questionnaire was to gather information about church life. The experimenter distributed the questionnaires, distributed and explained the informed consent form (see Appendix 4) and summarized the instructions for the informed consent form and the questionnaire, and encouraged participants to read and follow instruc- 
tions. Each subject was given a $\# 2$ pencil and an answer sheet (a computer scanned answer sheet) and was instructed to put answers on the answer sheet except for the final question, the open-ended question on tensions or conflict, which was to be answered on the questionnaire itself. Each minister filled out his questionnaires during the conference break times, while the experimenter remained nearby to answer any questions. The parishioners were encouraged to stay after the service, if they were willing to complete the questionnaire; the experimenter remained nearby to answer any questions. Approximately 50 percent of the parishioners in each church stayed to complete the questionnaire. Subjects were told that it would take approximately 30 minutes to complete the questionnaire; the participants did take approximately 30 minutes to complete it. After each participant completed the questionnaire, they were personally thanked for participating.

\section{Coding}

For the open-ended question (\#202 in Part Three of the questionnaire) on tension or conflict the two coders (independent raters) reviewed the responses. The two coders had been extensively trained in Transformational/Transactional distinctions for the earlier study. First, the coders made a determination as to whether responses were calling for more or less Transformational or Transactional behaviors and, second the coders attempted to label participants' responses without preconceived categories. The open-ended question read:

During the course of a pastorate sometimes tensions or conflicts arise over leadership issues. With this in mind, please complete the following: Parishioners and pastors would have less tension (conflict), if pastors (in their leadership role) would concentrate less on

and concentrate more on

In the first case, the two original coders also followed up on the third hypothesis; namely, that parishioners more frequently than pastors would relate Transactional rather than Transformational behaviors to reduced tensions. In this regard, coders determined whether each subject was suggesting that there would be less tension if pastors were less Transformational (or more Transactional). Coders also determined whether each subject was suggesting that there would be less tension if pastors were more Transformational (or less Transactional). The two coders had been trained in the basic Transformational/Transactional distinctions and were prepared to make such determinations. There was 100 percent 
agreement between the coders for these determinations. Because participants had two opportunities to respond concerning sources of tension (what I call the "concentrate less on" and the "concentrate more on" responses), participants could be credited with no, one, or two Transformational and/or Transactional responses.

In the second case, coders determined several categories into which the responses seemed to fall. Responses were tabulated by the coders as they were read; coders developed categories by reading the responses to the open-ended question (rather than working with preconceived categories). As can be seen in the open-ended question, participants had two opportunities to respond-what I call the "concentrate less on" and the "concentrate more on" responses. Coders attempted to label each part (partial response) of each participant's response. If a participant's response matched a category in the first section ("concentrate less on") of the question and also in the second section ("concentrate more on"), the category was recorded as having been matched twice. Three categories emerged as having frequent responses, while several smaller categories were dropped. The three categories that were kept had 35 or more responses, while the several categories that were not kept had 8 or less responses. The huge gap between those several categories having 8 or less responses and the three categories have 35 or more responses provided the basis for determining that only the three categories would be kept. Several of the categories were not kept, because they were mentioned too seldom-a total of 8 or less responses for each category. Three categories (congregation focused, spiritual domain, and control) were mentioned frequently (35 times or more). The label "Congregation focused" (Focused on the congregation and/or not focues on one or more of the following: programs, goals, ideas, or conflict) was mentioned 13 times by parishioners and 30 times by pastors; an example of a response in this category is: "... more on what parishioners needs are." The label "Spiritual Domain" (majoring on one or more of the following: the Bible, preaching, teaching, prayer, the example of Jesus, and guidance of God) was mentioned 25 times by parishioners and 10 times by pastors; an example of a response in this category is: "...more on using the Bible to guide and direct their problems." The label "Controlling" (in each case calling for the pastors to reduce tension by being less controlling, less power hungry, or less demanding) was mentioned by parishioners 14 times and by pastors 31 times; an example of a response in this category is: "...concentrate less on controlling the entire parish in the mind set..." The coders were in 100 percent agreement on labeling the partial responses and on the inclusion of those 123 (43 for congregation focused, 35 for spiritual domain, and 45 for controlling) partial responses (and, likewise, the exclusion of the other potential responses) in the above three categories. As mentioned earlier, it had been anticipated that inter-rater reliability 
between the two coders would be check utilizing Cohen's (1960) Kappa; because of the above mentioned 100 percent agreement, this statistic was not checked.

Prior to coding the responses to the open-ended question on tension into categories, the independent raters had received extensive training in coding processes and had worked together as coders in the earlier study (Bray, 1989) and in the earlier coding of the present study. The question was raised whether their prior collaboration reduced the trustworthiness (independence) of their coding procedure. To answer this post hoc question it was determined to have a third coder as well as one of the original coders independently code some of the original responses to the open-ended question. This took place four months after the original coding. The third coder was a member of the author's church; he holds a $\mathrm{PhD}$ from URI and has substantial background in research. To orient the new coder, the two original raters put in print the basis for their original coding scheme of the responses (see Appendix 5). The new coder received light training; that is, less than one half-hour of instruction. The responses of the first 15 pastors and the first 15 parishioners were utilized for this post hoc check; these responses included both the "concentrate less on" and the "concentrate more on" portions of the responses to the open-ended question. The results of the post hoc coding check were analyzed by Cohen's Kappa; the results indicated a moderate level of agreement with Cohen's Kappa $=0.78$. Krippendorff (1980) suggested that variables with agreements of less than 0.70 tend to be statistically insignificant; he further suggested that reliabilities between 0.67 and 0.80 be admitted only for drawing tentative conclusions.

In total there were 18 differences between the coding of the original coder and the third coder. As can be seen in the coding instructions (see Appendix 5), responses could be left unlabeled or each response could receive one or more labels; multiple labeling was allowed, not because of overlapping categories, but because of compound sentences, lists, etc. These features of the instructions were also given orally. Nevertheless, 13 of the 18 differences resulted from the third coder labeling responses that were left unlabeled by the original coder and 2 of the 18 differences resulted from the third coder not giving multiple labels where the original coder did. Perhaps the third coder was trying too hard to give each response one and only one label. How might this happen? Answers to this question could include that the third coder was somehow intimidated by the prospect of letting responses go unlabeled or was more broadly interpreting the three categories (especially the "Congregation Focused" category) than the original coders or that the orignial coders had more training and experience (i.e., were more sophisticated) than the third coder. The otherwise general agreement of the original coder and the third coder substantiates the original coding process. 
This coding check reinforces the importance of the three categories to pastors and parishioners. This coding check particularly demonstrated the stability of the coding process for the "Controlling" and the "Spiritual Domain" labels. The open-ended question on tension and the coding of responses to the question were utilized to find categories that are important to pastors and parishioners. These categories were then, if possible, to be used to statistically compare pastor parishioner responses in the "successful pastor" and the "unsuccessful pastor" sections.

Subsequent to the above coding check, a fourth coder was utilized to check on the coding that categorized responses as Transformational, Transactional, or other. The fourth coder, a professor in Experimental Psychology, was familiar with Transformational/Transactional distinctions through working with the author both on his thesis and this present dissertation. The responses of the first 15 pastors and the first 15 parishioners were utilized for this post hoc check; these responses included both the "concentrate less on" and the "concentrate more on" portions of the responses to the open-ended question. The fourth coder and one of the original coders were given the coding manual from the previous study and asked to code each of the 60 responses as Transformational, Transactional, or other; they were cautioned to code a response as Transformational or Transactional only if such a coding was clearly indicated. The results of the post hoc coding check were analyzed by Cohen's Kappa; the results indicated a moderate level of agreement with Cohen's Kappa $=0.74$. 


\section{RESULTS}

The Basic Transformational/Transactional Distinction Investigated through the 46 Statements

Introduction.

Each of the 46 Transformational/Transactional statements called for a Likert-type response on a five point scale (" $\mathrm{A}$ " indicates "strong importance," " $\mathrm{B}$ " indicates "mild importance," " $\mathrm{C}$ " indicates "undecided," " $\mathrm{D}$ " indicates "mild unimportance," or " $\mathrm{E}$ " indicates "strong unimportance." Participants were first asked to respond to forty-six (46) statements while being instructed to describe 'a successful pastor' and, second, they were asked to respond to the same statements again to describe 'an unsuccessful pastor'. The 46 items in Part One of the questionnaire include 23 Transformational items and 23 Transactional items that may be descriptive of pastors as leaders (see Appendix 1). In both sections of Part One of the questionnaire the scoring for the 23 Transformational statements was 5 for " $\mathrm{A}$," 4 for "B," 3 for " $C$," 2 for " $D$," and 1 for " $E$ " responses, while the scoring for the 23 Transactional statements was 1 for "A," 2 for "B," 3 for "C," 4 for "D," and 5 for " $E$ " responses.

Thus, for any participant on any item the a higher score reflected a more Transformational response, while a lower score reflected a more Transactional response. The responses to Part One of the questionnaire were analyzed first by two Principal Component Analyses (PCAs) and follow up Multivariate Analyses of Variance (MANOVAs), and second by two overall t-tests, and third by MANOVAs and follow up $t$-tests on the "Love Factor." Each of the statistical analyses was computed on the SAS System statistical package. For $t$-test analyses both PROC TTEST and and the sub-test Cochran were available on SAS; in each case ease of data entry was the determining factor as to which of the two procedures was utilized.

The Principal Component Analyses (PCAs).

The first hypothesis $\left(\mathrm{H}_{1}\right)$ was that pastors would respond more Transformationally (higher mean scores on the "successful pastor" section and lower mean scores on the "unsuccessful pastor" section) relative to parishioners regarding this basic leadership distinction. This basic distinction was addressed first by comparing the pastors' responses to the parishioners' responses on the "successful pastor" in Part One of the questionnaire. Initially, an overall $t$-test comparing pastors' to parishioners' responses on the 46 items (questions 1-46) in the "successful pastor" section was planned and an overall t-test 
comparing pastors' to parishioners' responses on the 46 items (questions 61-106) in the "unsuccessful pastor" section was also planned. However, once factors were extracted from Principal Component Analyses (PCAs), as discussed below, the presumed unity of the 46 items (in both sections of Part One of the questionnaire) was shattered. The hypothesis could be better tested on the individual factors extracted by the PCAs (discussed below).

The two PCAs were performed on the "successful pastor" and the "unsuccessful pastor" sections; the PCAs themselves were performed without hypothesis. The reason for this is that these PCAs are not being used here to develop a scale for further studies, but only to explore potential variables or factors that lie behind pastor and parishioner views of leadership. In effect, the PCAs are used here only for descriptive purposes. Typically, a PCA requires ten (10) or more participants per item and it is used to identify factors in a scale and to reduce the number of items to a manageable number for future versions of the scale. However, the PCAs performed for this study are considered as preliminary and are used herein to provide only descriptive rather than statistical corroboration of the information gained in Part Three, the open-ended question on possible tensions between pastors and parishioners, of the questionnaire. It will be recalled that the Forty-six (46) statements found in both sections of Part One of the questionnaire had been drawn from a literature review on Transformational leadership.

Participants in the study included forty-four (44) pastors and forty-two (42) parishioners. To provide factor stability for the PCAs ninety-six (96) URI students completed on the "successful pastor" and the "unsuccessful pastor" portions of the questionnaire. Their responses were to have been combined with those from the pastors and parishioners and to have been utilized to identify the PCA factors. Unfortunately, PCAs with the student data provided different factor structures for both the "successful pastor" and the "unsuccessful pastor" sections than did PCAs utilizing only the pastor and parishioner data. The student data were not directly related to the hypotheses of this study. Thus, the student generated data were neither further analyzed nor combined with pastor and parishioner data, because only the latter two groups of research participants are of interest in this study.

Separate PCAs were run on the 46 items (questions 1-46), the "successful pastors," and on the same 46 items (questions 61-106), the "unsuccessful pastors" of Part One of the questionnaire. The PCAs were run on the SAS program requesting Procedure Factor; to aid in interpretation and reducing the items in each factor, Varimax Rotation, scree analysis, and Cronbach's Coefficient Alpha were requested. (For mean and standard item deviation 
scores for the "successful pastor" and the "unsuccessful pastor" sections see Table 1). The PCA factors were labeled by the experimenter (see Tables 2 and 3). For the purposes of labeling individual factors, emphasis was given to those items that had the highest loadings in the factor. Only those Factor items that had loadings of 0.40 or greater were retained; items with loadings under 0.40 and items which were complex (those loading 0.40 or higher on one factor and loading within 0.25 of that loading on another factor) were eliminated. A scree analysis (Cattell, 1966) was performed for the PCA for "successful pastors" and for the PCA for "unsuccessful pastors" sections of part one of the questionnaire. In both cases, the scree could be read to break after four (4) factors. On this basis, four (4) factors were requested for each of the two PCAs. For the "successful pastor" PCA calling for four factors, the variance explained by each factor after Varimax rotation is Factor 1, "broadly Transformational" -13 percent, Factor 2, "Stability and Risk Avoidance" -12 percent, Factor 3, "Risk and Change" -8 percent, and Factor 4 , "Stability" -6 percent for a total of 39 percent. For the "unsuccessful pastor" PCA calling for four factors, the variance explained by each factor after Varimax rotation is Factor 1, "risk and change" -18 percent, Factor 2, "broadly Transactional" -12 percent, Factor 3, "Risk Averse" -9 percent, and Factor 4 (not labeled) -8 percent for a total of 47 percent. Internal consistency for the above PCAs was measured by use of Cronbach's Coefficient Alpha; the overall alpha for the "successful pastor" PCA was 0.76 (see Table 4), and for the "unsuccessful pastor" PCA was 0.71 (see Table 5). Both the Principal Components Analyses and the Multivariate Analyses of Variance were computed on the SAS System statistical package.

A Multivariate Analysis of Variance (MANOVA) was performed on the four factors derived from the PCA of the "successful pastor" and a second one was performed on the four factors derived from the PCA of the "unsuccessful pastor." The MANOVAs were run on the SAS program requesting Procedure GLM. In each case the 4 dependent variables (DVs) were the individual PCA factors (Factors 1, 2, 3, and 4). In each case the two independent variables (IVs) were the pastors and the parishioners. Generally, PCA factors are statistically analyzed in several ways to aid in the development of a list of items. In each case the factors generated through these PCAs were statistically analyzed by MANOVAs and $t$-tests to determine support or rejection of the first hypothesis.

The "Successful Pastor."

The first MANOVA was on the four factors of the "successful pastor" section of Part One of the questionnaire. This was a one factor MANOVA with two levels-pastors and 


\begin{tabular}{lcccc} 
& \multicolumn{4}{c}{ Overall Statistics } \\
& Pastor & \multicolumn{2}{c}{ Parishioner } \\
& Mean & StD & Mean & StD \\
"Successful Pastor" & 3.477 & 0.253 & 3.296 & 0.251 \\
"Unsuccessful Pastor" & 2.482 & 0.398 & 2.813 & 0.352
\end{tabular}

\section{"SUCCESSFUL PASTOR" SECTION}

Item number

Item

1 is concerned with growth

2 is comfortable with guidelines

3 is comfortable without guidelines

4 is comfortable with pressure situations

5 is interested in changing or transforming

6 is fairly modest about expressing compassion

7 is comfortable with shifts in expectations

8 sometimes takes risks

9 encourages change

10 frees people by setting boundaries

11 is fairly free to express love

12 provides permission to take risks

13 considers the past in decisions

14 is fairly free to express concern for you

15 avoids pressure situations

16 has a wait and see attitude

17 makes big changes

18 is concerned with needs you haven't expressed

19 is involved in his job description

20 focuses on short-term

21 is interested in doing better things

22 is fairly modest about expressing concern for you

23 warns against taking risks

24 frees people to make own boundaries

25 avoids shifts in expectations

26 says "don't count your chickens before they hatch"

27 rarely takes risks

28 encourages others to respect leadership

29 sometimes encourages shifts in power

30 is innovative
Mean StD

$\begin{array}{ll}4.81 & 0.45 \\ 1.71 & 0.80 \\ 3.00 & 1.41 \\ 3.99 & 1.05 \\ 4.45 & 0.78 \\ 3.11 & 1.46 \\ 3.64 & 1.06 \\ 4.33 & 0.94 \\ 4.34 & 0.78 \\ 2.36 & 1.05\end{array}$

$4.53 \quad 0.76$

$4.01 \quad 0.97$

$1.93 \quad 1.02$

$\begin{array}{ll}4.65 & 0.73\end{array}$

$3.74 \quad 1.67$

$3.53 \quad 1.22$

$2.83 \quad 1.16$

$4.30 \quad 0.80$

$1.94 \quad 1.16$

$3.66 \quad 1.03$

$\begin{array}{ll}4.41 & 0.92\end{array}$

$3.10 \quad 1.27$

$3.36 \quad 1.29$

$3.51 \quad 1.16$

$3.25 \quad 1.20$

$3.21 \quad 1.18$

$3.89 \quad 1.13$

$1.43 \quad 0.71$

$3.89 \quad 0.93$

$\begin{array}{ll}4.60 & 0.74\end{array}$ 
31 is involved beyond his job description

$\begin{array}{ll}4.36 & 0.85\end{array}$

32 usually discourages shifts in power

$3.41 \quad 1.08$

33 focuses on long-term

$4.33 \quad 0.94$

34 is concerned with needs you have expressed

$1.34 \quad 0.73$

35 is satisfied

$2.84 \quad 1.34$

36 is inquisitive

$4.29 \quad 0.86$

37 says "cast your bread upon the waters"

$3.94 \quad 1.04$

38 is fairly free to express compassion

$\begin{array}{ll}4.51 & 0.87\end{array}$

39 considers the future in decisions

$4.71 \quad 0.51$

40 is interested in preserving or stabilizing

$2.24 \quad 1.17$

41 encourages stability

$\begin{array}{ll}1.60 & 0.82\end{array}$

42 is fairly modest about expressing love

$3.08 \quad 1.29$

43 is concerned with stability

$\begin{array}{ll}1.75 & 0.92\end{array}$

44 is interested in doing things better

$1.23 \quad 0.45$

45 encourages others to take leadership

$4.80 \quad 0.40$

46 makes small changes

$2.19 \quad 0.98$

\section{"UNSUCCESSFUL PASTOR" SECTION}

61 is concerned with growth

$\begin{array}{ll}2.29 & 1.59\end{array}$

62 is comfortable with guidelines

$3.26 \quad 1.43$

63 is comfortable without guidelines

$3.30 \quad 1.51$

64 is comfortable with pressure situations

$1.91 \quad 1.23$

65 is interested in changing or transforming

$2.37 \quad 1.44$

66 is fairly modest about expressing compassion

$2.46 \quad 1.27$

67 is comfortable with shifts in expectations

$2.36 \quad 1.38$

68 sometimes takes risks

$2.75 \quad 1.47$

69 encourages change

$2.39 \quad 1.42$

70 frees people by setting boundaries

$3.45 \quad 1.28$

71 is fairly free to express love

$2.36 \quad 1.33$

72 provides permission to take risks

$2.58 \quad 1.38$

73 considers the past in decisions

$3.34 \quad 1.49$

74 is fairly free to express concern for you

$2.38 \quad 1.33$

75 avoids pressure situations

$2.29 \quad 1.49$

76 has a wait and see attitude

$2.08 \quad 1.36$

77 makes big changes

$3.11 \quad 1.63$

78 is concerned with needs you haven't expressed

$2.32 \quad 1.38$

79 is involved in his job description

$3.24 \quad 1.55$

80 focuses on short-term

$1.89 \quad 1.14$ 


\section{TABLE 1-MEAN AND STANDARD DEVIATION SCORES FOR THE PCA ITEMS (cont.)}

81 is interested in doing better things

$2.51 \quad 1.45$

82 is fairly modest about expressing concern for you

$2.71 \quad 1.31$

83 warns against taking risks

$2.45 \quad 1.41$

84 frees people to make own boundaries

$2.84 \quad 1.44$

85 avoids shifts in expectations

$2.68 \quad 1.34$

86 says "don't count your chickens before they hatch"

$2.38 \quad 1.39$

87 rarely takes risks

$2.21 \quad 1.48$

88 encourages others to respect leadership

$3.16 \quad 1.54$

89 sometimes encourages shifts in power

$2.83 \quad 1.44$

90 is innovative

$1.97 \quad 1.21$

91 is involved beyond his job description

$2.32 \quad 1.52$

92 usually discourages shifts in power

$2.39 \quad 1.36$

93 focuses on long-term

$1.97 \quad 1.18$

94 is concerned with needs you have expressed

95 is satisfied

$3.29 \quad 1.41$

96 is inquisitive

$2.32 \quad 1.27$

97 says "cast your bread upon the waters"

$2.61 \quad 1.27$

98 is fairly free to express compassion

$2.29 \quad 1.25$

99 considers the future in decisions

$2.18 \quad 1.27$

100 is interested in preserving or stabilizing

2.63

1.49

101 encourages stability

$3.01 \quad 1.36$

102 is fairly modest about expressing love

$2.78 \quad 1.25$

103 is concerned with stability

$2.75 \quad 1.43$

104 is interested in doing things better

$3.59 \quad 1.40$

105 encourages others to take leadership

$2.13 \quad 1.31$

106 makes small changes

3.04

1.40 


\section{TABLE 2-"SUCCESSFUL PASTOR" FACTOR LABELS AND LOADINGS}

FACTOR ONE, BROADLY TRANSFORMATIONAL, OFTHE SUCCESSFUL PASTOR PCA

Item

11 is fairly free to express love

30 is innovative

36 is inquisitive

38 is fairly free to express compassion

18 is concerned with needs you haven't expressed

33 focuses on long-term

1 is concerned with growth
Factor 1 Factor 2 Factor 3 Factor 4

$\begin{array}{llll}0.72 & 0.04 & 0.02 & -0.10\end{array}$

$\begin{array}{llll}0.70 & 0.14 & 0.15 & 0.04\end{array}$

$\begin{array}{llll}0.63 & 0.08 & 0.24 & -0.04\end{array}$

$\begin{array}{llll}0.61 & -0.01 & -0.16 & -0.15\end{array}$

$\begin{array}{llll}0.57 & 0.05 & 0.01 & -0.31\end{array}$

$\begin{array}{llll}0.49 & 0.02 & 0.14 & -0.19\end{array}$

$\begin{array}{llll}0.47 & -0.00 & -0.08 & -0.01\end{array}$

FACTOR TWO, STABILITY AND RISK AVOIDANCE, OF THE SUCCESSFUL PASTOR PCA

Item Factor 1 Factor 2 Factor 3 Factor 4

27 rarely takes risks

$-0.22$

0.77

0.07

$-0.20$

22 is fairly modest about expressing concern

$$
\text { for you }
$$

0.17

0.71

$-0.18$

$-0.06$

15 avoids pressure situations

$-0.01$

0.69

0.02

0.05

42 is fairly modest about expressing love

0.12

0.67

$-0.08$

0.20

16 has a wait and see attitude

$-0.01$

0.64

$-0.13$

0.09

23 warns against taking risks

0.07

0.63

0.02

0.15

6 is fairly modest about expressing compassion

$-0.04$

0.58

$-0.26$

$-0.18$

20 focuses on short-term

$-0.09$

0.55

$-0.19$

$-0.03$

35 is satisfied

$-0.31$

0.45

$-0.03$

0.03

FACTOR THREE, RISK AND CHANGE, OF THE SUCCESSFUL PASTOR PCA

\section{Item}

12 provides permission to take risks

5 is interested in changing or transforming

9 encourages change

17 makes big changes

7 is comfortable with shifts in expectations
Factor 1 Factor 2 Factor 3 Factor 4

$\begin{array}{rrrr}0.08 & -0.03 & 0.75 & -0.11 \\ 0.09 & 0.05 & 0.74 & 0.04 \\ 0.06 & 0.23 & 0.72 & -0.13 \\ -0.09 & -0.25 & 0.62 & -0.05 \\ 0.19 & -0.18 & 0.50 & 0.07\end{array}$

FACTOR FOUR, STABILITY, OF THE SUCCESSFUL PASTOR PCA

Item

43 is concerned with stability

46 makes small changes
Factor 1 Factor 2 Factor 3

$-0.17$

0.33

0.17

0.12

$-0.09$
Factor 4

0.62

0.47 
TABLE 3-"UNSUCCESSFUL PASTOR" FACTOR LABELS AND LOADINGS

FACTOR ONE, RISK AND CHANGE, OF THE UNSUCCESSFUL PASTOR PCA

Item

69 encourages change

68 sometimes takes risks

72 provides permission to take risks

65 is interested in changing or transforming

97 says "cast your bread upon the waters"

90 is innovative

99 considers the future in decisions

64 is comfortable with pressure situations

67 is comfortable with shifts in expectations

89 sometimes encourages shifts in power

61 is concerned with growth

96 is inquisitive
Factor 1 Factor 2 Factor 3 Factor 4

$\begin{array}{rrrr}0.84 & 0.07 & 0.20 & -0.02 \\ 0.75 & 0.08 & 0.09 & -0.17 \\ 0.72 & 0.07 & 0.34 & -0.01 \\ 0.66 & -0.15 & -0.05 & 0.17 \\ 0.64 & 0.03 & -0.09 & 0.13 \\ 0.61 & -0.10 & 0.12 & 0.27 \\ 0.59 & -0.46 & -0.05 & 0.12 \\ 0.58 & -0.25 & -0.08 & 0.22 \\ 0.53 & -0.05 & 0.01 & 0.17 \\ 0.53 & -0.00 & 0.02 & -0.18 \\ 0.51 & -0.43 & -0.20 & 0.03 \\ 0.46 & -0.23 & 0.04 & 0.34\end{array}$

FACTOR TWO, BROADLY TRANSACTIONAL, OF THE UNSUCCESSFUL PASTOR PCA

\section{Item}

101 encourages stability

62 is comfortable with guidelines

103 is concerned with stability

100 is interested in preserving or stabilizing

73 considers the past in decisions

94 is concerned with needs you have expressed

106 makes small changes

79 is involved in his job description

104 is interested in doing things better
Factor

$-0.15$

$-0.16$

0.02

$-0.04$

$-0.34$

$-0.52$

$-0.20$

$-0.30$

$-0.66$
Factor 2

0.79

0.73

0.72

0.68

0.53

0.49

0.48

0.43

0.41
Factor 3 Factor 4

$0.09-0.07$

$0.12-0.00$

$0.36 \quad-0.03$

$\begin{array}{ll}0.35 & 0.29\end{array}$

$0.05 \quad-0.17$

$0.18-0.26$

$-0.07 \quad-0.19$

$0.06 \quad-0.03$

$0.12-0.14$

FACTOR THREE, RISK AVERSE, OF THE UNSUCCESSFUL PASTOR PCA

\section{Item}

102 is fairly modest about expressing love

83 warns against taking risks

82 is fairly modest about expressing concern for you

87 rarely takes risks

86 says "don't count your chickens before they hatch"

85 avoids shifts in expectations

92 usually discourages shifts in power
Factor 1 Factor 2

$-0.10$

0.21

$-0.16$

0.28

0.07

0.00

0.07
0.24

0.25

$-0.04$

0.14

$-0.05$

0.03

0.07
Factor 3

0.67

0.66

0.63

0.57

0.55

0.50

0.49
Factor 4

0.00

0.03

$-0.02$

0.12

0.08

0.08

$-0.15$

FACTOR FOUR (LEFT UNLABELED) OF THE UNSUCCESSFUL PASTOR PCA

Item

80 focuses on short-term

78 is concerned with needs you haven't expressed
Factor 1

$-0.08$

0.37
Factor 2

0.08

$-0.07$
Factor 3

0.07

$-0.09$
Factor 4

0.69

0.68 
TABLE 4-CRONBACH's COEFFICIENT ALPHA FOR THE "SUCCESSFUL PASTOR" (an internal consistency measure)

\section{Successful Pastor PCA}

Factor 1

"Broadly Transformational"

Deleted Item
0.76 Raw Variables

0.77 Raw Variables

Raw Variables
$\begin{gathered}\text { Correlation Alpha } \\ \text { with total }\end{gathered}$

11 is fairly free to express love

0.63

30 is innovative

0.61

0.72

36 is inquisitive

0.49

0.74

38 is fairly free to express compassion

0.44

0.75

18 is concerned with needs you haven't expressed

0.55

0.73

33 focuses on long-term

0.41

0.77

1 is concerned with growth

0.38

0.76

Factor 2

0.83 Raw Variables

"Stability and Risk Avoidance"

Deleted Item

Raw Variables Correlation
with total Alpha

27 rarely takes risks

0.63

0.80

22 is fairly modest about expressing concern for you

0.68

0.79

15 avoids pressure situations

0.60

0.80

42 is fairly modest about expressing love

0.60

0.80

16 has a wait and see attitude

0.46

0.82

23 warns against taking risks

0.50

0.82

6 is fairly modest about expressing compassion

0.52

0.81

20 focuses on short-term

0.47

0.82

35 is satisfied

0.37

0.83

Factor 3

0.74 Raw Variables

"Risk and Change"

Deleted Item

12 provides permission to take risks

5 is interested in changing or transforming

Raw Variables

9 encourages change

Correlation with total

Alpha

0.52

0.69

17 makes big changes

0.64

0.66

0.57

0.68

7 is comfortable with shifts in expectations

0.58

0.71

0.40

0.74 
TABLE 4-CRONBACH's COEFFICIENT ALPHA FOR THE "SUCCESSFUL PASTOR" (cont.)

Factor 4

"Stability"

Deleted Item

43 is concerned with stability

46 makes small changes
0.32 Raw Variables

Raw Variables

Correlation with total

Alpha

0.19

0.19 
TABLE 5-CRONBACH's COEFFICIENT ALPHA FOR THE "UNSUCCESSFUL PASTOR"

Unsuccessful Pastor PCA

Factor 1

"Risk and Change"

Deleted Item

69 encourages change

68 sometimes takes risks

72 provides permission to take risks

65 is interested in changing or transforming

97 says "cast your bread upon the waters"

90 is innovative

99 considers the future in decisions

64 is comfortable with pressure situations

67 is comfortable with shifts in expectations

89 sometimes encourages shifts in power

61 is concerned with growth

96 is inquisitive
0.71 Raw Variables

0.87 Raw Variables

Factor 2

0.87 Raw Variables

Raw Variables

$\begin{array}{cr}\begin{array}{c}\text { Correlation } \\ \text { with total }\end{array} & \text { Alpha } \\ 0.74 & \\ 0.58 & 0.85 \\ 0.57 & 0.86 \\ 0.65 & 0.86 \\ 0.55 & 0.86 \\ 0.60 & 0.86 \\ 0.60 & 0.86 \\ 0.63 & 0.86 \\ 0.52 & 0.86 \\ 0.39 & 0.87 \\ 0.52 & 0.87 \\ 0.46 & 0.87 \\ & 0.87\end{array}$

"Broadly Transactional"

Deleted Item

Raw Variables

$\begin{array}{cc}\begin{array}{c}\text { Correlation } \\ \text { with total }\end{array} & \text { Alpha } \\ 0.77 & \\ 0.69 & 0.84 \\ 0.70 & 0.84 \\ 0.60 & 0.84 \\ 0.53 & 0.85 \\ 0.67 & 0.86 \\ 0.40 & 0.85 \\ 0.47 & 0.87 \\ 0.57 & 0.86 \\ & 0.8\end{array}$

101 encourages stability

62 is comfortable with guidelines

0.84

103 is concerned with stability

100 is interested in preserving or stabilizing

73 considers the past in decisions

0.85

94 is concerned with needs you have expressed

0.85

106 makes small changes

0.87

79 is involved in his job description

0.57

0.8

104 is interested in doing things better

0.73 Raw Variables

Factor 3

"Broadly Transactional"

Deleted Item

Raw Variables

Correlation

with total

102 is fairly modest about expressing love

0.56

Alpha

83 warns against taking risks

0.52

0.67

0.45

0.68

82 is fairly modest about expressing concern for you

0.45

0.69

87 rarely takes risks

0.42

0.69

86 says "don't count your chickens before they hatch"

0.36

0.70

85 avoids shifts in expectations

0.32

0.71

92 usually discourages shifts in power

0.72 
TABLE 5-CRONBACH's COEFFICIENT ALPHA FOR THE "UNSUCCESSFUL PASTOR" (cont.)

Factor 4

(left unlabeled)

Deleted Item

0.59 Raw Variables

Deleted Item

Raw Variables
$\begin{gathered}\text { Correlation Alpha } \\ \text { with total }\end{gathered}$

80 focuses on short-term

0.42

78 is concerned with needs you haven't expressed

0.42 
parishioners. The four dependent variables were the four PCA factors. The Wilk's Lambda statistic for the MANOVA has a value of 0.87 , with $F=2.77(\mathrm{df}=4)$ and eta squared at 0.23 , which is significant at the 0.05 level. Since the Wilk's Lambda statistic was significant, there was justification for examining which factor(s) demonstrated a significant difference between pastors and parishioners.

Prior to analyzing individual factors, the factors were reduced to their individual marker variables (see Tables 2 and 4). I use the term "marker variable" to refer to an item that has a loading of 0.40 or higher and that loads at least 0.25 higher on the specific factor than on any of the other factors; the numbers, 0.40 and 0.25 are commonly used in limiting factors to marker items. Factors can more easily be labeled and interpreted after the items have been reduced to their marker variables. MANOVAs were performed on each of the four factors after they were reduced to their individual marker variables. The MANOVAs were run on the SAS program requesting Procedure GLM. Each of the four one-factor MANOVAs has two levels-pastors and parishioners and the several items as the dependent variables (DVs). Factor One, labeled "broadly Transformational" was not significant; Cronbach's Coefficient Alpha, a measure of internal consistency, is $\mathbf{0 . 7 7}$ for this "broadly Transformational" factor. As is common with first and second factors, this factor's elements were very broad; all 7 of the marker variables were Transformational statements. Factor Two, labeled "Stability and Risk Avoidance," was significant at the 0.05 level; the Wilk's Lambda statistic for this "Stability and Risk Avoidance" factor has a value of 0.75 , with $F=2.67(\mathrm{df}=9)$ and eta squared at 0.25. Cronbach's Coefficient Alpha is 0.83 for this second factor. On Factor two pastors describe "successful pastors" as more willing to risk and to change (as more Transformational than Transactional) than do parishioners. This finding was in support of the first hypothesis. All 9 of the marker variables were Transactional statements. Factor Three, labeled "Risk and Change," was not significant; Cronbach's Coefficient Alpha is 0.74 for this third factor. All 5 of the marker variables were Transformational statements. Factor Four, labeled "Stability," was not significant; Cronbach's Coefficient Alpha was 0.32. There were only two marker variables; both marker variables were Transactional statements.

The "Unsuccessful Pastor".

The four factors of the "unsuccessful pastor" were also analyzed by a MANOVA; this was a one factor MANOVA with two levels-pastors and parishioners-and the dependent variables being the four PCA factors. The Wilk's Lambda statistic for this MANOVA has a value of 0.83 , with $F=3.52(\mathrm{df}=4)$, which is significant at the 0.05 level (see Table 7). Since 
the Wilk's Lambda statistic was significant, there was justification for looking at which factor(s) demonstrated a significant difference between pastors and parishioners.

Prior to looking at the individual factors of the "unsuccessful Pastor PCA, the factors were reduced to their individual marker variables (see Tables 3 and 5). Again, I use the term "marker variable" to refer to an item that has a loading of 0.40 or higher and that loads at least 0.25 higher on the specific factor than on any of the other factors. MANOVAs were performed on each of the four factors after they were reduced to their individual marker variables. Each of the four one-factor MANOVAs has two levels-pastors and parishioners-and the four PCA factors as the dependent variables (DVs). Factor One, labeled as "Risk and Change," was significant at the 0.05 level; the Wilk's Lambda statistic for the MANOVA has a value of 0.74 , with $F=2.01(\mathrm{df}=12)$ and eta squared at 0.26 . The Cronbach Coefficient Alpha is 0.87 . As is common with first and second factors, this factor's elements were very broad; all 12 of the marker variables were Transformational statements. For this "Risk and Change" factor Parishioners describe "unsuccessful pastors" as more willing to risk and change than do pastors. Factor Two, labeled as "broadly Transactional," was significant at the 0.05 level; the Wilk's Lambda statistic for the MANOVA has a value of 0.74, with $F=2.83(d f=9)$ and eta squared at 0.26. The Cronbach Coefficient Alpha is 0.87. On this factor pastors describe "unsuccessful pastors" as more Transactional rather than Transformational than do parishioners. This finding was in support of the first hypothesis. All 9 of the marker variables were Transactional statements. Factor Three, labeled as "Risk Averse," was not significant; Cronbach's Coefficient Alpha is 0.59. All 7 marker variables of Factor Three are Transactional statements. Factor Four, not labeled because the two items seemed to have little in common, was not significant; the Cronbach Coefficient Alpha was 0.59. One marker variable was Transformational and the other was Transactional.

\section{The Overall $t$-tests.}

To test the first hypothesis, an overall $t$-test comparing pastors' to parishioners' responses on the 46 items (questions 1-46) in the "successful pastor" section was planned. An overall $t$-test comparing pastors' to parishioners' responses on the 46 items (questions 61-106) in the "unsuccessful pastor" section was also planned. However, once factors were extracted from the PCAs, it seemed more reasonable to test the hypotheses on the individual factors extracted by the PCAs. On the other hand, in order to check for possible differences across the two sections ("successful pastor" and "unsuccessful pastor"), I decided to perform two overall $t$-tests (within groups) to address the first hypothesis again in a different way. 
As described in the previous section, Multivariate Analysis of Variance (MANOVAs) demonstrated a significant difference between pastors (the first IV) and parishioners (the second IV) on several of the factors (DVs); each of these differences were in support of the first hypothesis. It was assumed that the overall $t$-test for pastors in support of the first hypothesis would demonstrate that pastors see "successful pastors" significantly more Transformational than "unsuccessful pastors." The overall $t$-test for parishioners was performed without hypothesis. These $t$-tests were run on the SAS program requesting $t$-test Cochran.

An overall $t$-test comparing pastors' responses on the 46 items describing a "successful pastor" to their responses to the same 46 items describing an "unsuccessful pastor" was performed. The result was significant at the 0.05 level $(\mathrm{df}=40)$ with $\mathrm{t}=20.29$ with the proportion of variance accounted for, eta squared, equal to 0.91 , which is a strong experimental effect. As hypothesized, pastors assumed that "successful pastors" would be more Transformational versus Transactional than would be "unsuccessful pastors" (see Table 6).

Then, an overall $t$-test comparing parishioners' responses on the 46 items describing a "successful pastor" to their responses to the same 46 items describing an "unsuccessful pastor" was performed. The result was significant at the 0.05 level $(\mathrm{df}=30)$ with $\mathrm{t}=13.04$ with the proportion of variance accounted for, eta squared, equal to 0.85 , which is a strong experimental effect. Parishioners assumed that "successful pastors" would be more Transformational versus Transactional than would be "unsuccessful pastors" (see Table 6). In sum, the four overall mean statistics (see Table 1) have the highest mean (most Transformational or least Transactional) associated with the pastors' view of the "successful pastor," the next highest mean with the parishioners' view of the "successful pastor," the third highest mean with the parishioners' view of the "unsuccessful pastor," and the lowest mean with the pastors' view of the "unsuccessful pastor."

Part One of the Questionnaire--the "Love Factor."

The six statements comprising the "Love Factor" are:

"fairly free to express love,"

"fairly modest about expressing love,"

"fairly free to express compassion,"

"fairly modest about expressing compassion,"

"fairly free to express concern for you," and

"fairly modest about expressing concern for you." 
TABLE 6-t-TESTS COMPARING "SUCCESSFUL" WITH "UNSUCCESSFUL" PASTORS

Overall $t$-test comparing pastors' responses to questions 1-46, the "successful pastor" section, with their responses to questions 61-106, the "unsuccessful pastor" section

$\begin{array}{lllll}\text { Category } & \underline{\text { Mean Difference }} & \underline{\mathrm{t}} & \underline{\mathrm{N}} & \mathrm{p} \\ \text { Pastors } & 1.773 & 20.29 & 41 & <0.05\end{array}$

Overall $t$-test comparing parishioners' responses

to questions 1-46, the "successful pastor" section, with their responses to questions 61-106, the "unsuccessful pastor" section

$\begin{array}{lllll}\text { Category } & \underline{\text { Mean Difference }} & \underline{\mathrm{t}} & \underline{\mathrm{N}} & \mathrm{p} \\ \text { Parishioners } & 1.271 & 13.04 & 31 & <0.05\end{array}$


TABLE 7-LEAST SQUARE MEANS FOR THE "LOVE FACTOR" ITEMS

Least Square Means from the MANOVA for the "Successful Pastor"

\begin{tabular}{lllllll} 
Status & Q6 & Q11 & Q14 & Q22 & Q38 & Q42 \\
\hline Pastors & & & & & & \\
Parishioners & 3.48 & 4.48 & 1.41 & 2.66 & 1.43 & 2.73 \\
& 2.76 & 4.60 & 1.26 & 3.02 & 1.48 & 3.05
\end{tabular}

Least Square Means from the MANOVA for the "Unsuccessful Pastor"

\begin{tabular}{lllllll} 
Status & Q66 & Q71 & Q74 & Q82 & Q98 & Q102 \\
\hline Pastors & & & & & & \\
Parishioners & 2.41 & 2.41 & 3.77 & 3.43 & 3.77 & 3.43 \\
& 2.62 & 2.17 & 3.48 & 3.05 & 3.79 & 2.81
\end{tabular}


Multivariate Analyses of Variance (MANOVAs) were run on the six "love items" included both in the "successful pastor" section and the "unsuccessful pastor" sections. These were both one factor MANOVAs with two level-pastors and parishioners-and the dependent variables were the six "love items." These MANOVAs were run on the SAS program requesting Procedure GLM. These analyses were also performed without hypotheses. Neither MANOVA was significant. The individual item mean scores were inspected, because of the exploratory nature of this part of the study, despite these nonsignificant MANOVAs (see Table 7). These six "love items" were purposely included in the study, because of questions raised in the previous study (Bray, 1989). In the earlier study responses concerning the "love factor" seemed to contradict the literature. Therefore, individual item mean scores were inspected (see Table 7). Five of the six items in the "successful pastor" section of the PCA revealed more Transformational versus Transactional scores (higher means) for the pastors than for the parishioners. Likewise, five of the six items in the "unsuccessful pastor" section of the PCA reveal more Transactional versus Transformational scores (lower means) for the pastors than for the parishioners. Again, despite the MANOVAs not being significant and because of the exploratory nature of this part of the study, $t$-tests were run comparing the pastors' responses on the "successful pastor" section to their responses on the "unsuccessful pastor" section (see Table 8). Likewise, $t$-tests were used for a similar comparison for the parishioners' responses (see Table 8). These $t$-tests were run on the SAS program requesting Procedure $t$-test. All six comparisons for the pastors were significant at the 0.008 level; because six separate $t$-tests were performed, the frequently utilized alpha level of 0.05 was split $(0.05 / 6=0.008)$ across the six tests. Pastors responded that "successful pastors" are more Transformationally loving than "unsuccessful pastors": items $6 / 66$ with a $t=4.26(N=44)$ with the proportion of variance accounted for, eta squared, equal to 0.30 ; items $11 / 71$ with a $t=9.24(\mathrm{~N}=44)$ with the proportion of variance accounted for, eta squared, equal to 0.67 ; items $14 / 74$ with a $t=11.63(\mathrm{~N}=44)$ with the proportion of variance accounted for, eta squared, equal to 0.76 ; items $22 / 82$ with a $t=2.97$ $(N=44)$ with the proportion of variance accounted for, eta squared, equal to 0.17 ; items $38 / 98$ with a $t=11.85(\mathrm{~N}=44)$ with the proportion of variance accounted for, eta squared, equal to 0.77; and items $42 / 102$ with a $t=3.21(\mathrm{~N}=44)$ with the proportion of variance accounted for, eta squared, equal to 0.19 . Three of the six comparisons for the parishioners were significant at the 0.008 level; again, because six separate $t$-tests were performed, the smaller alpha level was utilized. Parishioners responded that "successful pastors" are more Transformationally loving than "unsuccessful pastors": items $11 / 71$ with a $t=10.17(\mathrm{~N}=42)$ with the proportion of variance accounted for, eta squared, equal to 0.72 ; items $14 / 74$ with a $t=9.05(N=42)$ with the proportion of variance accounted for, eta squared equal to 0.67 ; and items $38 / 98$ with a 
$t=8.64(\mathrm{~N}=42)$ with the proportion of variance accounted for, eta squared, equal to 0.65 , which is a strong experimental effect (see Table 8).

The Basic Transformational/Transactional Distinction and the Three Transformational Sub-Dimensions

Introduction.

Part Two of the questionnaire contained four sections: Section One, items 121-199, addresses the basic Transformational/Transactional distinction; Section Two, items 181187, addresses the Transformational sub-dimension of Modeling; Section Three, question \#200, addresses the Transformational sub-dimension of Breadth of Involvement; and Section Four, question \#201, addresses the Transformational sub-dimension of Perseverance. The basic Transformational/Transactional distinction and the three sub-dimension had also been explored in the earlier study (Bray, 1989). That is, these sub-dimensions were not developed from factors derived from Principal Components Analyses.

The Basic Transformational/Transactional Distinction.

The first hypothesis is that pastors would respond more Transformationally (i.e., have a higher score) relative to parishioners regarding the basic Transformational/Transactional leadership distinction. This hypothesis had been tested in Part One of the questionnaire (as discussed above), and, again, in section one of Part Two of the questionnaire. In order to test the first hypothesis, a MANOVA was performed for section one, the nine questions on the basic Transformational/Transactional distinctions (questions 121-129). This was a one factor MANOVA with two levels-pastors and parishioners-and the dependent variables being the nine items in the section. The MANOVA was not significant; this analysis was run on the SAS program requesting Procedure GLM.

The Three Transformational Sub-Dimensions.

The second hypothesis was that pastors would respond more Transformationally relative to parishioners on the three Transformational sub-dimensions: Modeling, Breadth of Involvement, and Modeling. A MANOVA was performed to test this hypothesis on section two, the eight questions (questions 181-187) on the Transformational sub-dimension of Modeling; this was a factor MANOVA with two levels--pastors and parishioners-and the dependent variables being the seven items in the section. The MANOVA was not significant; this analysis was run on the SAS program requesting Procedure GLM. 


\section{TABLE $8-t$-TESTS FOR THE "LOVE FACTOR" ITEMS}

$t$-tests of pastors' responses on the "successful pastor" versus" unsuccessful pastor" (significance at the 0.008 level)

$\begin{array}{llccrl}\text { Items } & \text { N } & \text { Mean Difference } & \text { Std Error } & \text { T } & \text { Significance } \\ 6 / 66 & 44 & 1.07 & 0.25 & 4.26 & \text { Significant } \\ 11 / 71 & 44 & 2.07 & 0.22 & 9.24 & \text { Significant } \\ 14 / 74 & 44 & 2.36 & 0.20 & 11.63 & \text { Significant } \\ 22 / 82 & 44 & 0.77 & 0.26 & 2.97 & \text { Significant } \\ 38 / 98 & 44 & 2.34 & 0.20 & 11.85 & \text { Significant } \\ 42 / 102 & 44 & 0.70 & 0.22 & 3.21 & \text { Significant }\end{array}$

$t$-tests of parishioners' responses on the "successful pastor" versus" unsuccessful pastor" (significance at the 0.008 level)

$\begin{array}{llccrl}\text { Items } & \mathrm{N} & \text { Mean Difference } & \text { Std Error } & \mathrm{T} & \text { Significance } \\ 6 / 66 & 42 & 0.14 & 0.35 & 0.41 & \text { Not Significant } \\ 11 / 71 & 42 & 2.43 & 0.24 & 10.17 & \text { Significant } \\ 14 / 74 & 42 & 2.21 & 0.24 & 9.05 & \text { Significant } \\ 22 / 82 & 42 & 0.02 & 0.34 & 0.07 & \text { Not Significant } \\ 38 / 98 & 42 & 2.31 & 0.27 & 8.64 & \text { Significant } \\ 42 / 102 & 42 & -0.24 & 0.37 & -0.64 & \text { Not Significant }\end{array}$

Item 6/66 reads: "fairly free to express love,"

Item $11 / 71$ reads: "fairly modest about expressing love,"

Item $14 / 74$ reads: "fairly free to express compassion,"

Item 22/82 reads: "fairly modest about expressing compassion,"

Item 38/98 reads: "fairly free to express concern for you," and

Item 42/102 reads: "fairly modest about expressing concern for you." 
In addition, $t$-tests were performed to test the second hypothesis on Part Two of the questionnaire, section three (question \#200) on the Transformational sub-dimension of Breadth of Involvement and section four (question \#201) on the Transformational sub-dimension of Perseverance. Neither $t$-test was significant; these analyses were run on the SAS program requesting Procedure $t$-test Cochran.

The Open-Ended Question on Tension

Introduction.

Part Three of the questionnaire was the open-ended question on tension. The question read:

During the course of a pastorate sometimes tensions or conflicts arise over leadership issues. With this in mind, please complete the following: Parishioners and pastors would have less tension (conflict), if pastors (in their leadership role) would concentrate less on

and concentrate more on

The question was included for two purposes: 1) to address the third hypothesis and 2) to form a beginning point from which to discover statistical support for the assumption that differences between pastors and parishioners in church leadership perspectives result in tension.

The Third Hypothesis.

The third hypothesis was that parishioners more frequently than pastors would relate Transactional rather than Transformational behaviors to reduced tensions. That is, parishioners would anticipate that pastors would seek a Transactional approach to reducing tensions, while pastors would anticipate that pastors would seek a Transformational approach to reducing tensions.

As discussed earlier under "Coding," the responses to the open-ended question had to be coded before they could be statistically analyzed. Two coders (independent raters) reviewed the responses to determine categories into which the responses seemed to fall. To 
code the responses the approach taken on the open-ended question for this part of the analysis was that coders were to: 1 ) determine whether each subject suggested that there would be less tension if pastors were less Transformational (or more Transactional); and also 2) determine whether each subject was suggesting that there would be less tension if pastors were more Transformational (or less Transactional). As mentioned earlier, under Coding, it had been anticipated that inter-rater reliability between the two coders would be checked utilizing Cohen's (1960) Kappa. Because coder agreement was 100 percent, this assessment was not needed. Because participants had two opportunities to respond concerning sources of tension (what I call the "concentrate less on" and the "concentrate more on" responses), participants could be credited with no, one, or two Transformational and/or Transactional responses.

A Chi Square analysis was performed. The Chi Square was significant, $6.20(\mathrm{df}=1)$, at the 0.05 level. Pastors responded more often than parishioners that Transformational behaviors would reduce tension; parishioners responded more often than pastors that Transactional behaviors would reduce tension (see Table 9). The results of the Chi Square analysis supported the third hypothesis.

\section{Label Comparison.}

This series of studies has investigated whether there are differences between pastors and parishioners in leadership perspective and, if so, whether those differences lead to tensions between pastors and parishioners. If this second condition is true, the next step in the series of studies is to investigate whether such tensions are connected with shortened pastoral tenure. One of the purposes of the open-ended question on tension was to identify categories related to tension. Once those categories were identified, they were to be compared to the labels given to the factors derived from the Principal Components Analyses (PCAs) discussed earlier.

As stated above, the two coders (independent raters) determined whether responses to the open-ended question called for more or less Transformational or Transactional behaviors. In addition to the above analysis, the two coders categorized the responses a second time. Again, as can be seen in the open-ended question, participants had two opportunities to respond concerning sources of tension-what I call the "concentrate less on" and the "concentrate more on" responses. For this part of the analysis, coders attempted to label each part (partial response) of each participant's response; if a participant mentioned a subject in 


\section{TABLE 9--TENSION CATEGORIES}

Below is a table of how many times more Transformational or more Transactional behavior was called for (as noted by the independent coders) by pastors and parishioners in the open-ended question (\#202) on tension.

\section{More Transformational More Transactional}

$\begin{array}{lll}\text { Pastor } & 23 & 0\end{array}$

Parishioner $\quad 9 \quad 3$

Below is a table of how many times each of the three categories were mentioned (as noted by the independent coders) by pastors and parishioners in the open-ended question (\#202) on tension.

\section{Controlling Spiritual Domain Congregation Focused}

$\begin{array}{llll}\text { Pastors } & 31 & 10 & 30 \\ \text { Parishioners } & 14 & 25 & 13\end{array}$

The label "Congregation focused" (in each case calling for the pastors to reduce tension by focusing on the people of the congregation rather than programs, goals, ideas, and/or conflict) was mentioned 13 times by parishioners and 30 times by pastors; an example of a response in this category is: "... concentrate more on what parishioners needs are."

The label "Spiritual Domain" (in each case calling for the pastors to reduce tension by focusing on the Bible, preaching, teaching, prayer, example of Jesus, and/or guidance of God) was mentioned 25 times by parishioners and 10 times by pastors; an example of a response in this category is: "...concentrate more on using the Bible to guide and direct their problems."

The label "controlling" (in each case calling for the pastors to reduce tension by being less controlling, power hungry, and/or demanding) was mentioned by parishioners 14 times and by pastors 31 times; an example of a response in this category is: "...concentrate less on controlling the entire parish in the mind set..." 
the first section ("concentrate less on") of the question and also in the second section ("concentrate more on"), the subject was recorded as having been mentioned twice. These categories were compared to PCA factors labels in a qualitative way; this comparison was pursued without hypothesis.

Three categories (Congregation Focused, Spiritual Domain, and Controlling) were mentioned frequently (35 times or more; see Table 9). The huge gap between those several categories having 8 or less responses and the three categories have 35 or more responses determined the number and type of categories to be kept. Several of the categories were not kept, because they were mentioned too seldom--a total of 8 or less responses for each category. The label "Congregation focused" (in each case calling for the pastors to reduce tension by focusing on the people of the congregation rather than programs, goals, ideas, and/or conflict) was mentioned 13 times by parishioners and 30 times by pastors; an example of a response in this category is: "... concentrate more on what parishioners needs are." The label "Spiritual Domain" (in each case calling for the pastors to reduce tension by focusing on the Bible, preaching, teaching, prayer, example of Jesus, and/or guidance of God) was mentioned 25 times by parishioners and 10 times by pastors; an example of a response in this category is: "...concentrate more on using the Bible to guide and direct their problems." The label "Controlling" (in each case calling for the pastors to reduce tension by being less controlling, power hungry, and/or demanding) was mentioned by parishioners 14 times and by pastors 31 times; an example of a response in this category is: "...concentrate less on controlling the entire parish in the mind set..." The coders were in $100 \%$ agreement on labeling the partial responses and on the inclusion of those 123 ( 43 for congregation focused, 35 for spiritual domain, and 45 for controlling) partial responses in the above three categories. As mentioned above and in under "Coding," it had been anticipated that inter-rater reliability between the two coders would be checked utilizing Cohen's (1960) Kappa; because there was $100 \%$ agreement, this statistic was not needed.

The three categories (Congregation Focused, Spiritual Domain, and Controlling) the coders had determined from the open-ended question ( $\# 202)$ were checked for potential matching with the labels of the PCA factors (see Tables 2 and 3) discussed under the results section for 46 Transformational/Transactional Statements; there were no such matches. This check was a visual comparison of the three category labels (Congregation Focused, Spiritual Domain, and Controlling) with the several PCA factor labels. 


\section{DISCUSSION}

\section{Introduction}

Three basic assumptions of my earlier research (Bray, 1989) were: 1) that there is a difference between pastors and parishioners in their perceptions of Transformational and Transactional leadership positions; 2) that this difference leads to friction (tension) between parishioners and pastors; and 3) that this friction (tension) causes pastors to have brief tenures. In the earlier study (Bray, 1989) only the first assumption was tested. Significant differences in the hypothesized direction that pastors are more Transformational than parishioners were found for the basic Transformational/Transactional distinction and for the Transformational sub-dimensions of Perseverance and Breadth of Involvement. One element (the "love factor") of the Modeling sub-dimension of leadership was identified as particularly important to the parishioners (i.e., listed by the parishioners more than all other elements combined on the relevant open-ended questions), but not the pastors.

For this present study it was also assumed that: (1) pastors are more Transformational than parishioners; (2) these differences produce tension (conflict) in pastor/parishioner relationships; 3 ) this tension causes pastors to have brief tenures. This third assumption is not directly investigated in this present study.

First, the internal consistency of the 23 Transformational statements and the 23 Transactional statements utilized in the Principal Components Analyses is discussed. Second, each of the three hypotheses is discussed. Third, the investigations that were pursued without hypothesis are addressed.

\section{Internal Consistency of the PCAs}

The 23 pairs of Transformational and Transactional statements had been developed from the Coding Manual (see Appendix 2) used in the earlier study (Bray, 1989). The Coding Manual was used as the basis for coding the responses to the open-ended questions utilized in that earlier study; those responses were coded as as Transformational, Transactional, or Other. The Coding Manual, in turn, had been developed from the literature search.

The measure of internal consistency for the "successful pastor" section, Cronbach's Coefficient Alpha, was 0.76. The measurés of internal consistency for the first three factors were all relatively high; respectively they were $0.77,0.83$, and 0.74 . All 7 of the marker 
variables for Factor One, the "broadly Transformational" factor, were Transformational statements. All 9 of the marker variables for Factor Two, the "stability and risk avoidance" factor, were Transactional statements. All 5 of the marker variables for Factor Three, the "risk and change" factor, were Transformational statements. These 21 statements (marker variables) appear to consistently measure what they purport to measure.

The measure of internal consistency for the "unsuccessful pastor" section, Cronbach's Coefficient Alpha, was 0.71 . The measures of internal consistency for the first three factors were all relatively high; respectively they were $0.87,0.87$, and 0.73 . All 12 of the marker variables for Factor One of the "unsuccessful pastor" section, the "broadly Transformational" factor, were Transformational statements. All 9 of the marker variables for Factor Two of the "unsuccessful pastor" section, the "broadly Transactional" factor, were Transactional statments. All 7 of the marker variables for Factor three of the "unsuccessful pastor" section, the "risk averse" factor, were Transactional statements. These 28 statements (marker variables) appear to consistently measure what they purport to measure.

\section{The Basic Transformational/Transactional Distinction}

The first hypothesis was that pastors would respond more Transformationally, that is, have higher mean scores on the "successful pastor" section and lower mean scores on the "unsuccessful pastor" section, relative to parishioners regarding this basic leadership distinction. This basic distinction was addressed first by comparing the pastors' responses to the parishioners' responses on the "successful pastor" section. After conducting Principal Component Analyses (PCAs) which identified factors, the hypothesis was tested on the individual factors. Two Multivariate Analyses of Variance (MANOVAs) were performed: one on the four factors ("broadly Transformational," "stability and risk avoidance," "risk and change," and "stability"; see Table 3) that were identified with the "successful pastor" and one on the four factors ("Risk and Change," "broadly Transactional," "Risk Averse," and a fourth factor that was left unnamed; see Table 5) that were identified with the "unsuccessful pastor."

The first MANOVA was carried out on the four factors of the "successful pastor" section of the questionnaire; the MANOVA was significant. The factor labeled "Stability and Risk Averse" was significant; on this factor pastors describe "successful pastors" as more willing to risk and more open to change than do parishioners. In the literature willingness to risk and openness to change are seen as Transformational. On the other hand, a common phrase 
associated with the Transactional leader is "status quo." Bennis and Nanus (1985) speak of Transformational leaders being "able of deploying their ideas and themselves into some consonance and thereby committing themselves to a greater risk..." Transformational leaders believe in their visions and are willing to accept change and risk to reach their visions. In the literature enthusiasm about change is associated with a Transformational perspective on leadership. Gordon (1987) says of Transformational leaders:

"They identify the triggers for a major change. They create a vision of the change. They become personally committed to the change and obtain subordinates' commitment as well. Finally, they institute change by managing the organization's structure, management processes, culture, and human resources" (p. 702).

Transformational leaders are interested in "second order change"; this term refers to major or fundamental shifts in attitudes, beliefs, needs, and values and dramatic increases in output, productivity, and quality (Bass, 1985b; Gibbons, 1986; Brown, 1987). On the other hand, Transactional leaders are interested in "first order change," which is defined in contrast to second order change as incremental, changes of degree, minor or routine shifts within the same context or framework (Bass, 1985, pp. 3-5; Brown, 1987). In either case, the changes may be in attitudes, programs, and/or organization. Tichy and Devanna (1986a) say that Transformational leaders identify themselves as change agents. All 9 of the marker variables for the "Stability and Risk Averse" Factor are Transactional statements ("marker variable" refers to an item that has a loading of 0.40 or higher and that loads at least 0.25 higher on the specific factor than on other factors).

The "Stability and Risk Averse" factor on the "successful pastor"-MANOVA adds support to the findings of the earlier study (Bray, 1989). In this case, when pastors and parishioners describe a "successful pastor," the pastors describe the "successful pastor" in a more Transformational rather than Transactional way than do the parishioners. It was important to verify the findings of the earlier study on the first hypothesis on pastor/parishioner differences before going to the next step in this series of studies. The next step is to relate these differences to tension between pastors and parishioners.

The second MANOVA conducted on the four factors of the "unsuccessful pastor" section was significant. Factor One, labled as "Risk and Change," was significant; on this factor pastors describe "unsuccessful pastors" as more Transactional than do parishioners. All 12 of the marker variables are Transfromational statements. As was discussed above in regard to the significant factor within the "successful pastor" framework, risk and change are basic 
distinguishing marks in the Transformational/Transactional literature. Factor Two, labeled as "broadly Transactional," was significant; on this factor pastors describe "unsuccessful pastors" as more Transactional than do parishioners. All but 2 of the 12 marker variables for the "broadly Transactional" Factor are Transactional statements.

Parishioners describe the "unsuccessful pastor" in a more Transformational than Transactional way relative to the pastors. One might speculate that pastors see a "successful pastors"" Transformationalism causing his success, while parishioners see an "unsuccessful pastor's" Transformationalism causing his failure. Bass (1985) sees any given leader as exhibiting a variety of patterns of Transformational and Transactional leadership. Burns (1978), on the other hand, suggested that for definitional purposes it is helpful to consider Transformational and Transactional leadership perspectives in contrast to one another-on opposite ends of a continuum. Since this is a study not of leaders individually, but of overall differences between pastors and parishioners, Burn's (1978) lead is followed. This tradition started by Burns is followed despite the fact that the dichotomous notion of continua is frequently questioned in some areas of contemporary psychology. In this study the PCA factors, which are orthogonal by definition, fairly consistently separate Transformational from Transactional item-statements; that is, each factor tends to have either Transformational or Transactional item-statements, but not both. This separation does not necessarily reject the notion that Transformationalism and Transactionalism are at opposite ends of a uni-dimensional continuum. It does suggest that Transformationalism and Transactionalism might be best considered as in a bi-dimensional space.

The results of the MANOVAs discussed above demonstrate pastors place "successful pastors" more toward the Transformational end of the continuum than do parishioners and also pastors place "successful pastors" more toward the Transformational end of the continuum than they place "unsuccessful pastors." The MANOVA results also demonstrate that parishioners place "successful pastors" more toward the Transactional end of the continuum than do pastors and parishioners also place "successful pastors" more toward the Transactional end of the continuum than they place "unsuccessful pastors."

As mentioned regarding the MANOVA for the "successful pastor," it was important to verify the findings of the earlier study on the first hypothesis on pastor/parishioner differences before going to the next step in this series of studies. The first MANOVA added some support the first hypothesis by analyzing pastor/parishioner differences relating to a "successful pastor," while the second MANOVA added further support to the same hypothesis 
by analyzing pastor/parishioner differences relating to an "unsuccessful pastor." This second verification is useful. As mentioned earlier, the next step is to relate these differences to tension between pastors and parishioners. As stated above, these results add weight to speculation about this second assumption. Not only do pastors and parishioners differ on the basic Transformational/Transactional distinction, they also differ as to how to describe both a successful and an unsuccessful pastor. We can speculate that these kinds of differences might lead to tension between pastors and parishioners.

While the MANOVAs add support to the findings of the earlier (Bray, 1989) study, they support them by factor clusters of Transformational and/or Transactional items rather than by - considering all 46 ( 23 Transformational statements and 23 Transactional statements) items at once. Once the PCAs were performed and factors were formed, it was less appropriate to also run overall $t$-tests on either the "successful pastor" or "unsuccessful pastor" items. However, it was appropriate to compare the two sections on "successful pastors" and "unsuccessful pastors." Two overall $t$-tests were performed, each comparing (mean difference) the "successful pastors" to the "unsuccessful pastors."

An overall $t$-test comparing the mean differences of pastors' responses on the 46 "successful pastor" items to their responses to the 46 "unsuccessful pastor" items was performed. The results were significant. Pastors assumed that "successful pastors" would be more Transformational than Transactional relative to "unsuccessful pastors" (see Table 8). Again, an overall $t$-test comparing the mean differences of parishioners' responses on the 46 items (questions 1-46, "successful pastor") to their responses to the same 46 items (questions 61-106, "unsuccessful pastor") was performed. The results were significant. Parishioners assumed that "successful pastors" would be more Transformational than Transactional relative to "unsuccessful pastors" (see Table 8). The significant Multivariate Analyses of Variance (MANOVAs) on the factors discussed above demonstrated that pastors saw "successful pastors" as more Transformational than do parishioners and that pastors saw "unsuccessful pastors" as more Transactional than do parishioners. The two overall t-tests look at the items without taking into account the factors formed by the PCAs. As stated above, pastors assumed that "successful pastors" would be more Transformational than Transactional relative to "unsuccessful pastors"; this finding offers additional support to the first hypothesis. Although there was no hypothesis, parishioners, likewise, assumed that "successful pastors" would be more Transformational than Transactional relative to "unsuccessful pastors." In sum, the four overall mean statistics (see Table 1) have the highest mean (most Transformational or least Transactional) associated with the pastors' view of 
the "successful pastor," the next highest mean with the parishioners' view of the "successful pastor," the third highest mean with the parishioners' view of the "unsuccessful pastor," and the lowest mean with the pastors' view of the "unsuccessful pastor."

The first hypothesis was also tested by asking participants to indicate (on a five-point Likert-type scale) how important they considered each of nine items in regard to a minister helping his church reach its potential and leading it to the future. The nine items (the pastor's development of a lay team, his love for the people, his presenting a vision, his goal setting, his goal monitoring, his compassion and concern for people, his concentrating on the future, his promotion of lay leadership, and his focus on the local community) were taken from the earlier (Bray, 1989) study. Several questions about the basic Transformational/Transactional distinction in the previous study were collapsed into the nine items for the present study. In addition, each of the nine items had been judged by the coders of the previous study as Transformational. A MANOVA was performed on these nine items, but the MANOVA was not significant. Comparison of the means on each the nine items demonstrates that pastors generally ( 7 of the 9 items) saw these items as more important than did the parishioners; this direction was as hypothesized. This finding, though not statistically significant, is an indication that this part of the study warrants further attention. My assumption is that a significant difference was not achieved because the items, as written, were so socially desirable on their face (validity) that the range of responses was restricted. Two of the items ("his presenting a vision" and "his goal monitoring") received only "strong importance" responses by every participant (both pastors and parishioners). One item ("his compassion and concern for people") received only "strong importance" and "mild importance" responses by the participants.

\section{The Three Transformational Sub-Dimensions}

The sub-dimensions of Transformationalism (Modeling, Perseverance, and Breadth of Involvement) were investigated in this study. The second hypothesis was that pastors would respond more Transformationally relative to parishioners on these sub-dimensions. In the previous study each of these sub-dimensions was investigated through several questions; in this present study the several questions were collapsed into one question for each sub-dimension.

The sub-dimension of Modeling was investigated; for this question participants were asked to indicate (on a five-point Likert-type scale) how important they considered each of seven behaviors and attitudes (the pastor's love for people, his optimism, his openness, his 
flexibility, his vision, his involvement in the lives of others, and his tolerance) that a minister might model before a congregation. The MANOVA performed on this sub-dimension was not significant. Again, the assumption is that significant difference was not achieved because the items, as written, were so socially desirable on their face (validity) that the range of responses was restricted. Two of the items ("his love for people" and "his openness") received only "strong importance" or "mild importance" responses by participants; three items ("his optimism," "his involvement in the lives of others," and "his tolerance") received only "strong importance," "mild importance," or "undecided" responses by the participants.

To investigate the Transformational sub-dimensions of Breadth of Involvement and Perseverance two $t$-tests were run. Both questions utilized a five-point Likert-type scale. The Breadth of Involvement question asked for an indication of agreement with ministers working beyond their job descriptions; the $t$-test was not significant. Harris (1985) notes that as a "conceptualizer" a Transformational leader "links together pieces and parts into a whole"; such a leader must attend to the whole, to the Breadth of ministry concerns. Likewise, Bennis and Nanus (1985) characterize the leader as one who becomes acquainted with and interested in every aspect of the organization. The notion of a pastor working within or beyond job description is useful in determining whether a perspective is Transformational (expecting a leader to work broadly beyond his job description) or Transactional (expecting a leader to work narrowly within his job description). The Perseverance question asked for an indication of agreement with ministers using their leadership skills to change parishioners' minds. This second $t$-test was also not significant. As with the other two sections in Part Two of the questionnaire, there was a restricted range of responses. For the Breadth of Involvement question all but 7 of 86 participants responded with either 'strong agreement' or 'mild agreement'. For the Perseverance question all but 13 of 86 participants responded with either 'strong agreement' or 'mild agreement'. These two questions also may have suffered from being toward the end of a 30 minute questionnaire; in addition, the next and final question is of a different nature-an open-ended question-and, thus, may have contributed to participants giving less than full attention to the two questions.

In the earlier study (Bray, 1989) the hypothesis concerning the Transformational sub-dimensions of Breadth of Involvement and Perseverance was supported by the results. Those results were not supported in this present study. Further, the results of the investigation in the earlier study were unclear for the Transformational sub-dimension of Modeling. Unfortunately, the results of this present study do little to clarify potential differences between pastors and parishioners on Modeling. 


\section{Tensions and Transformational/Transactional Issues}

The third hypothesis was that parishioners more frequently than pastors would relate Transactional rather than Transformational behaviors to reduced tensions; i.e., that parishioners more often than pastors would see pastors' emphasis on Transformational concerns rather than the parishioners' Transactional needs resulting in tension. This hypothesis was explored through responses to the open-ended question on tension. The question was framed so that participants might respond as to what pastors might "concentrate less on" and as to what pastors might "concentrate more on" in order to reduce tension between pastors and parishioners.

Although the coders were to later look for categories within the responses that might relate to the PCA factor labels, in order to investigate this third hypothesis, they were first asked only to look for Transformational/Transactional responses. A precise method of analysis for the open-ended question had not been predetermined, because of the unpredictable nature of responses to open-ended question.

In order to investigate the third hypothesis, the coders determined 1) whether each subject was suggesting that there would be less tension if pastors were less Transformational (or more Transactional) and the coders also determined 2) whether each subject was suggesting that there would be less tension if pastors were more Transformational (or less Transactional). Pastors responded more often than parishioners that Transformational behaviors would reduce tension; parishioners responed more often than pastors that Transactional behaviors would reduce tension. The results of the Chi Square analysis supported the third hypothesis. Given these findings, we can speculate that tensions are likely to grow if, in an attempt to reduce tensions, pastors increase their Transformational behaviors, while parishioners associate reduced tensions with less Transformational behavior on the part of pastors. Earlier, it was stated that for definitional purposes Burns (1978) began a tradition of looking at Transformationalism and Transactionalism as opposite perspectives on a continuum. Also stated was that Bass (1985) sees any given leader as exhibiting a variety of patterns of Transformational and Transactional leadership. Likewise, Brown (1987) says, "The most successful transformational leaders are supported by their ability to manage the day-to-day events that implement their agendas (i.e., transact with subordinates)" (pp.2930). Regardless of definitions, pastors and parishioners should note that pastors are likely to attempt to reduce tensions in their churches by increased reliance on Transformational attitudes and actions; since parishioners relate Transactional attitudes and actions to reduced 
tensions, in such a situation tensions, despite good intentions, might increase. Whether this potential escalation of tensions results in brief tenures must be left to the next study in this series.

\section{The Open-Ended Question and the PCA Factors}

In addition to the coding activity to determine whether responses to the open-ended question were Transformational or Transactional, the two coders (independent raters) reviewed the responses and determined several sub-categories into which the responses seemed to fall more specifically in regard to tension. Three such categories were kept, because of the high number of responses that fell into those categories. The label "Congregation focused" (in each case calling for the pastors to reduce tension by focusing on the people of the congregation rather than programs, goals, ideas, and/or conflict) was mentioned 13 times by parishioners and 30 times by pastors; an example of a response in this category is: "... concentrate more on what parishioners' needs are." The label "Spiritual Domain" (in each case calling for the pastors to reduce tension by focusing on the Bible, preaching, teaching, prayer, example of Jesus, and/or guidance of God) was mentioned 25 times by parishioners and 10 times by pastors; an example of a response in this category is: "...concentrate more on using the Bible to guide and direct their problems." The label "Controlling". (in each case calling for the pastors to reduce tension by being less controlling, power hungry, and/or demanding) was mentioned by parishioners 14 times and by pastors 31 times; an example of a response in this category is: "...concentrate less on controlling the entire parish in the mind set..."

The area of tension was investigated without hypothesis as to what categories might develop. Klubnik (1984; see Appendix 6) gave an opportunity for pastors to state some of their frustrations with pastoral ministry. He listed several descriptions of such frustrations under each of the following headings: "Resistance to Change": "Board (i.e., the ruling church board) Conflict," "Pleasing People," and "Discouragement."

The coders had determined that none of the three categories (Congregation Focused, Spiritual Domain, and Controlling) from the open-ended question matched with any of the PCA factors.

What have we discovered about tension between pastors and parishioners? In the open-ended question "Controlling" is related to tension. In that same open-ended question parishioners see Transactional attitudes and actions as potentially reducing tension, while 
pastors see Transformational attitudes and actions as potentially reducing tension; pastors tended to say that tensions would be reduced by increased Transformational behavior and attitudes, while parishioners tended to say that tensions would be reduced by increased Transactional behaviors and attitudes. Callahan (1990) has recently pointed out that leaders' efforts to reduce member dissatisfactions are less productive in the short-run than increasing member satisfactions. The Transformational literature suggests that organizational members, who are as a group more likely to have a Transactional orientation, tend to be more concerned with their heritage and present needs, while the Transformational leader is more concerned with the present and the future. The members know that the old things done in the old ways produce certain results; they do not always see a beneficial link (that is in the mind of the leader) between themselves and new things done in new ways. As stated in the "Principal Literature and Definition" section, Transformational change is rewarded only after an extended time, whereas Transactional change may be rewarded relatively quickly. Because followers do not see the rewards of Transformational change as quickly as they do a Transactional change, the need for greater Perseverance in a Transformational leader can be seen intuitively. The leader must have a long-term orientation and must be willing to make enemies and to be unloved.

Transformational literature suggests that Transformational leaders tend to persevere. In the earlier study (Bray, 1989) we discovered that pastors tend to see the need for persevering when their are pastor- parishioner conflicts, while parishioners expect pastors to bow to the collective will of the parishioners. If a pastor finds himself in a time of conflict or tension with his parishioners, he should particularly attend to the parishioners' Transactional concerns and temporarily down-plan his Transformational concerns. If the tensions are reduced, he can then reintroduce his Transformational concerns. The results of this study suggest that if he were to maintain or increase his Transformational behavior in a time of tension, his parishioners would experience increased tension.

The model I see emerging from these studies is that pastoral Transformational behaviors tend to increased parishioner tension, while pastoral Transactional behaviors tend to reduce tension. A pastor must be earning credits through Transactional behavior, if he is to have the people's support for his Transformational goals. Transformationism is what an organization needs for tomorrow, while Transactionism is what the people of the organization want today. A leader should always be interested both in tomorrow and his people. In fact, the only way that people will support him or her in the tomorrow-issues, is for the leader to demonstrate a genuine interest in the today-needs of the people. 
Clearly, there is a potential link between the Transformational/Transactional difference between pastors and parishioners and the tension they experience. Perhaps, this link can be further substantiated in future research; if so, the third assumption of this series of studies, that the tension between pastors and parishioners because of differing perspectives on Transformational/Transactional Leadership results in brief tenures for pastors, should be investigated.

\section{The "Love Factor"}

One pair of contrasting Transformational/Transactional statements, which I have called "the love factor," derived from the earlier study (Bray, 1989) was examined herein without hypothesis. In the Coding Manual (see Appendix 2) for the earlier study this pair of contrasting statements read as follows: "concerned beyond expressed needs (love, compassion, and concern for others) versus addresses only expressed needs"; this pair has been expanded in the present study to three pairs of statements: "fairly free to express love" and "fairly modest about expressing love," "fairly free to express compassion" and "fairly modest about expressing compassion," and "fairly free to express concern for you" and "fairly modest about expressing concern for you."

We have assumed that pastors by virtue of their role and training are more Transformational than parishioners. Transformational leadership theory in general would predict that pastors, if they are more Transformational than parishioners, would have more Transformational attitudes and behaviors (fairly free to express love, compassion, and concern) than parishioners (fairly modest about expressing love, compassion, and concern). This did not prove to be the case in the earlier (Bray, 1989) study, based on information gathered by open-ended questions on the Transformational sub-dimension of Modeling; the "love factor" provided more of the responses judged to be Transformational by the coders than the rest of the modeling aspects combined. On the one hand, consistent with Transformational theory one could assume that pastors would be more Transformational than pastors. On the other hand, the church gives a central position to the teaching on love has and parishioners gave considerably greater emphasis to this factor in the earlier study. Therefore, I made no hypothesis regarding a possible significant difference on this variable. In this present study, participants had opportunity to respond directly to different aspects of this factor.

The earlier study (Bray, 1989) led me to two rival hypotheses concerning the "love factor." First, it may be that parishioners and pastors see this dimension as equally important, 
but for different reasons; thus, the parishioner is saying, "If you will demonstrate (model) these in your own behavior, the church will grow (Questions 7 and 8 from the previous study) and I will personally follow you (Questions 17 and 18 from the previous study)," while the pastor is saying, "I exhibit certain things, not to promote growth or to inspire parishioners to follow me, but out of conviction." Second, it may be that pastors do not realize how important this dimension is to the parishioners either to have the church run smoothly or to have the parishioners follow them. Since the earlier study raised important questions about possible pastor/parishioner differences, analysis of the "love factor" was included in this present study.

Because both the MANOVA for the six "love factor" items in the "successful pastor" PCA section and the MANOVA of the same items in the "unsuccessful pastor" PCA section were not significant, we can call into question that pastors see the expressing of love, compassion, or concern as less important to successful pastoring than do parishioners. In fact, this study gives reason to suggest that pastors as leaders fit the image of the stereotype (free to express love, compassion, and concern) of the Transformational leader as found in the literature. Though the MANOVAs were not significant, five of the six items in the "successful pastor" section of the PCA revealed more Transformational versus Transactional scores (higher means) for the pastors than for the parishioners (see Table 9). Likewise, five of the six items in the "unsuccessful pastor" section of the PCA reveal more Transactional versus Transformational scores (lower means) for the pastors than for the parishioners (see Table 9). Additionally, even though the MANOVAs were not significant, because of the exploratory nature of this part of the study, $t$-tests were run comparing the pastors' responses on the "successful pastor" section to their responses on the "unsuccessful pastor" section; likewise, $t$-tests made a similar comparison for the parishioners' responses. All six comparisons for the pastors were significant at the 0.05 level; on each of the items pastors described "successful pastors" more Transformationally loving than "unsuccessful pastors." Again, the six items were: "fairly free to express love" and "fairly modest about expressing love," "fairly free to express compassion" and "fairly modest about expressing compassion," and "fairly free to express concern for you" and "fairly modest about expressing concern for you." Three of the six comparisons for the parishioners were significant at the 0.05 level; on each of these items parishioners, likewise responded that "successful pastors" would be more Transformationally loving than "unsuccessful pastors." Interestingly, all three of these comparisons were the Transformationally framed items: "is fairly free to express love," "is fairly free to express concern for you," and "is fairly free to express compassion." Perhaps, parishioners are clear on their convictions about those who freely express in these areas, but 
are vague as to what it means to be modest in these areas. The results of these $t$-test would suggest that pastors are aware (indeed, more aware than parishioners) that "successful pastors" are more Transformationally loving than "unsuccessful pastors."

In education the question has been raised, "If the student has not learned, has the teacher taught?" When we consider the earlier study (Bray, 1989) together with this present study, the following question might be raised: "If the parishioners indicate a desire to be loved, has the pastor, despite his Transformational views on love, loved?" There may be a gap between what pastors hold as Transformational conviction and what the parishioners are experiencing. The mixed results across the two studies suggest that parishioners should clamor for the love they miss and pastors should concentrate on exhibiting the love they are assumed to have.

\section{Limitations}

Several methodological concerns arise. First, the subject sampling was one of convenience. The pastors represented those who attended the specific denominational meeting. The parishioners represented those who attended their respective mid-week services in the four churches selected by the investigator. Second, the investigator alone made the judgment on labeling the several Principal Components Analysis (PCA) factors. Third, during the coding process, the pastors' responses were in one stack and the parishioners' responses were in another. To avoid potential coder bias, responses should have been randomly and blindly coded. Fourth, the four sections of Part Two of the questionnaire need to be reworked. The 9 items comprising section one on the basic Transformational/Transactional distinction and the 7 items comprising section two on the Transformational sub-dimension of Modeling did not significantly differentiate between pastors and parishioners. My assumption is that significant difference was not achieved because the items, as written, were so socially desirable on their face that the range of responses was restricted. Perhaps an opposite item could be developed for each of the present items; then, each of the items could be paired with an opposite and participants (subjects) could make a forced choice between two items in each case. Sections three and four may have suffered from being toward the end of a long questionnaire. The pastor participants were anxious to finish the questionnaire and visit with colleagues at the conference. The parishioner participants were anxious to go home; they completed the questionnaire somewhere between 8 and 9 o'clock after an hour long meeting. Fifth, the coding training and process and the instructions need to be strengthened. Specifically, when independent coders were requested to label a response into one or more 
categories, a unit ' of analysis problem developed. Also, the original coders had extensive and parallel training, while the third and fourth coders received light and independent training. Sixth, the subject sampling was very small. Seventh and finally, Because the number of participants was restricted, the Principal Components Analyses (PCAs) were preliminary; the results of the work included in the PCAs must be considered as tentative.

\section{Conclusions}

The basic concept of Transformational/Transactional church leadership warrants more study. Further analysis of the responses to the PCA items utilized in this study will allow for the development of an abbreviated questionnaire. The approach taken to investigate the basic Transformational/Transactional distinction utilizing items 121-129 and the sub-dimension of Modeling utilizing items 181-187 can be refined by contrasting those questionnaire items with their polar opposites (because this was not done herein, we received a restricted range of responses), and, thereby, received a 'forced-choice' response from participants. The earlier study (Bray, 1989) raised questions about the "love factor" and pastor/parishioner consistency with Transformational theory; this present study demonstrated that when pastors are directly asked about the six items which comprised this factor, the results are consistent with Transformational theory.

Three basic assumptions of this research are that there is a difference between pastors and parishioners along Transformational/Transactional lines, that this difference leads to tension between parishioners and pastors, and that this tension causes pastors to have brief tenures. This study has reaffirmed the validity of the first assumption; the second assumption is shown to have some merit; and the third assumption is yet to be addressed.

A future study might incorporate into a list that includes some of the 46 items (found in the "successful pastor" and "unsuccessful pastor" sections) additional items that develop the concerns found in the areas (Congregation Focused, Spiritual Domain, and Controlling) from the open-ended question on tension and items from Klubnik's (1984; see Appendix 6) list of frustrations with pastoral ministry. The present list's schema has for each Transformational statement a corresponding Transactional statement; a future study could utilize insights from this present study to abbreviate this list and could add further items, while maintaining the present schema. Valuable insights into pastoral-parishioner tension might be gained from examining how PCA factors cluster the previously utilized Transformational and Transactional statements (items) and the newer items, which include Klubnik's frustra- 
tion categories ("Resistance to Change": "Board (i.e., the ruling church board) Conflict," "Pleasing People," and "Discouragement") and the issues raised in the open-ended question on tension.

A future study might also explore tension together with the "love factor." The fact that the two different approaches (Bray, 1989, and this present study) gave differing results regarding the "love factor" raises the question that tensions might arise from mutual misinterpretation within a given church system.

A future study might also explore situational factors such as size of church, region-specific traits, age of church, etc.

This is the second study for this approach to leadership in a religious setting; comparative studies may prove beneficial. This was a study of Conservative Baptist pastors and parishioners in the Northeastern United States. Future studies could explore geographic locations other than the Northeast and other denominations. 


\section{APPENDIX 1: QUESTIONNAIRE}

\section{QUESTIONNAIRE-PART ONE, SECTION ONE-A SUCCESSFUL PASTOR*}

This page requires 46 responses; utilize numbers 1-46 on the blue and white answer sheet to indicate your responses. You will be filling in the appropriate circle, A, B, C, D, E, as indicated. There are a number of descriptions that might represent a pastor as a church leader. They are in no particular order; there are no right or wrong answers. I am interested in the extent to which you agree that each statement agrees with your concept of "a SUCCESSFUL pastor." For each description fill in the appropriate circle on the computer score sheet to indicate your level of agreement that the statement describes a successful pastor.

Filling in ' $A$ ' indicates strong agreement

Filling in ' $B$ ' indicates mild agreement

Filling in ' $\mathrm{C}$ ' indicates a neutral response

Filling in ' $D$ ' indicates mild disagreement

Filling in ' $E$ ' indicates strong disagreement

\section{IN MY ESTIMATION, A SUCCESSFUL PASTOR...}

1 is concerned with growth

2 is comfortable with guidelines

3 is comfortable without guidelines

4 is comfortable with pressure situations

5 is interested in changing or transforming

6 is fairly modest about expressing compassion

7 is comfortable with shifts in expectations

8 sometimes takes risks

9 encourages change

10 frees people by setting boundaries

11 is fairly free to express love

12 provides permission to take risks

13 considers the past in decisions

14 is fairly free to express concern for you

15 avoids pressure situations

16 has a wait and see attitude

17 makes big changes

18 is concerned with needs you haven't expressed

19 is involved in his job description

20 focuses on short-term

( ${ }^{\star}$ The actual questionnaire was on $81 / 2$ by 14 inch paper; thus, page one included the Part One, section one, page two included Part One, section two, and page three included the remainder of the questionnaire.) 


\section{QUESTIONNAIRE-PART ONE, SECTION ONE-A SUCCESSFUL PASTOR (cont.)*}

21 is interested in doing better things

22 is fairly modest about expressing concern for you

23 warns against taking risks

24 frees people to make own boundaries

25 avoids shifts in expectations

26 says "don't count your chickens before they hatch"

27 rarely takes risks

28 encourages others to respect leadership

29 sometimes encourages shifts in power

30 is innovative

31 is involved beyond his job description

32 usually discourages shifts in power

33 focuses on long-term

34 is concerned with needs you have expressed

35 is satisfied

36 is inquisitive

37 says "cast your bread upon the waters"

38 is fairly free to express compassion

39 considers the future in decisions

40 is interested in preserving or stabilizing

41 encourages stability

42 is fairly modest about expressing love

43 is concerned with stability

44 is interested in doing things better

45 encourages others to take leadership

46 makes small changes

( ${ }^{\star}$ The actual questionnaire was on $81 / 2$ by 14 inch paper; thus, page one included the Part One, section one, page two included Part One, section two, and page three included the remainder of the questionnaire.) 


\section{APPENDIX 1: QUESTIONNAIRE (cont.)}

\section{QUESTIONNAIRE-PART ONE, SECTION TWO-An UNSUCCESFUL PASTOR*}

This page requires 46 responses; utilize numbers $61-106$ on the blue and white answer sheet to indicate your responses. You will be filling in the appropriate circle, A, B, C, D, and $\mathrm{E}$, as indicated. There are a number of descriptions that might represent a pastor as a church leader. They are in no particular order; there are no right or wrong answers. I am interested in the extent to which you agree that each statement agrees with your concept of "an UNSUCCESSFUL pastor." For each description fill in the appropriate circle on the computer score sheet to indicate your level of agreement that the statement describes an unsuccessful pastor.

Filling in ' $A$ ' indicates strong agreement

Filling in ' $B$ ' indicates mild agreement

Filling in ' $\mathrm{C}$ ' indicates a neutral response

Filling in ' $D$ ' indicates mild disagreement

Filling in ' $E$ ' indicates strong disagreement

\section{IN MY ESTIMATION, AN UNSUCCESSFUL PASTOR...}

61 is concerned with growth

62 is comfortable with guidelines

63 is comfortable without guidelines

64 is comfortable with pressure situations

65 is interested in changing or transforming

66 is fairly modest about expressing compassion

67 is comfortable with shifts in expectations

68 sometimes takes risks

69 encourages change

70 frees people by setting boundaries

71 is fairly free to express love

72 provides permission to take risks

73 considers the past in decisions

74 is fairly free to express concern for you

75 avoids pressure situations

76 has a wait and see attitude

77 makes big changes

78 is concerned with needs you haven't expressed

79 is involved in his job description

80 focuses on short-term

( The actual questionnaire was on $81 / 2$ by 14 inch paper; thus, page one included the Part One, section one, page two included Part One, section two, and page three included the remainder of the questionnaire.) 
QUESTIONNAIRE-PART ONE, SECTION TWO-An UNSUCCESFUL PASTOR (cont.)*

81 is interested in doing better things

82 is fairly modest about expressing concern for you

83 warns against taking risks

84 frees people to make own boundaries

85 avoids shifts in expectations

86 says "don't count your chickens before they hatch"

87 rarely takes risks

88 encourages others to respect leadership

89 sometimes encourages shifts in power

90 is innovative

91 is involved beyond his job description

92 usually discourages shifts in power

93 focuses on long-term

94 is concerned with needs you have expressed

95 is satisfied

96 is inquisitive

97 says "cast your bread upon the waters"

98 is fairly free to express compassion

99 considers the future in decisions

100 is interested in preserving or stabilizing

101 encourages stability

102 is fairly modest about expressing love

103 is concerned with stability

104 is interested in doing things better

105 encourages others to take leadership

106 makes small changes

( ${ }^{*}$ The actual questionnaire was on $81 / 2$ by 14 inch paper; thus, page one included the Part One, section one, page two included Part One, section two, and page three included the remainder of the questionnaire.) 


\section{APPENDIX 1: QUESTIONNAIRE (cont.)}

\section{QUESTIONNAIRE PART TWO*}

For questions 121-129 and 181-187, I would like you to indicate how important these items are to you. Please indicate your responses on the blue and white answer sheet---

Filling in ' $A$ ' indicates strong importance

Filling in ' $B$ ' indicates mild importance

Filling in ' $\mathrm{C}$ ' indicates you are undecided

Filling in ' $D$ ' indicates mild unimportance

Filling in ' $E$ ' indicates strong unimportance

SECTION ONE-121-129-A minister wants to help his church reach its potential and to lead his church to the future. If he is to be effective, how important is each of these factors?

121 his development of a lay team

122 his love for the people

123 his presenting a vision

124 his goal setting

125 his goal monitoring

126 his compassion and concern for people

127 his concentrating on the future

128 his promotion of lay leadership

129 his focus on the local community $\triangle B C D E$

$\triangle \mathrm{BCDE}$

A BCDE

$\triangle B C D E$

$\triangle B C D E$

$\triangle B C D E$

$\triangle B C D E$

A BCDE

$\triangle B C D E$

SECTION TWO-181-187-You may have heard the old adage "Some things are better caught than taught." How important would it be to catch each of the following from your minister?

181 his love for people

182 his optimism

183 his openness

184 his flexibility

185 his vision

186 his involvement in the lives of others

187 his tolerance $\triangle B C D E$

A BCDE

$\triangle B C D E$

$\triangle B C D E$

$\triangle B C D E$

$\triangle B C D E$

$\triangle \mathrm{BCDE}$

( ${ }^{*}$ The actual questionnaire was on $81 / 2$ by 14 inch paper; thus, page one included the Part One, section one, page two included Part One, section two, and page three included the remainder of the questionnaire.) 


\section{APPENDIX 1: QUESTIONNAIRE (cont.)}

\section{QUESTIONNAIRE PART TWO (cont.)*}

For questions 200 and 201, I would like you to indicate your level of agreement. Please indicate your responses on the blue and white answer sheet.

Filling in " $A$ " indicates strong agreement

Filling in " $\mathrm{B}$ " indicates mild agreement

Filling in " $\mathrm{C}$ " indicates a neutral position

Filling in " $\mathrm{D}$ " indicates mild disagreement

Filling in " $\mathrm{E}$ " indicates strong disagreement

SECTION THREE-200—Churches have expectations of their ministers; sometimes these expectations may be found in written job descriptions. Some ministers provide leadership beyond the job description areas and others provide leadership only within the job description areas. Do you agree with a pastor providing leadership beyond the job description areas (please fill in $A, B, C, D$, or $E$ )?

SECTION FOUR-201-Suppose there are differences between the pastor and parishioners. He has a choice between accepting their position as final or using his leadership skills to attempt to change their minds. In this situation do you agree with a minister using leadership skills to change their minds (please fill in $A, B, C, D$, or $E$ )?

\section{QUESTIONNAIRE PART THREE}

Question 202 requires you to complete the statement below. Please com plete both parts of the statement.

202 During the course of a pastorate sometimes tensions or conflicts arise over leadership issues. With this in mind, please complete the following: Parishioners and pastors would have less tension (conflict), if pastors (in their leadership role) would concentrate less on

and concentrate more on

( ${ }^{\star}$ The actual questionnaire was on $81 / 2$ by 14 inch paper; thus, page one included the Part One, section one, page two included Part One, section two, and page three included the remainder of the questionnaire.) 


\section{APPENDIX: 2 TRANSFORMATIONAL/TRANSACTIONAL CONTRASTS FROM EARLIER (Bray, 1989) CODING MANUAL}

\begin{tabular}{|c|c|}
\hline TRANSFORMATIONAL & TRANSACTIONAL \\
\hline $\begin{array}{l}\text { future oriented } \\
\text { willing to take risks } \\
\text { interested in improving } \\
\text { innovative } \\
\text { inquisitive }\end{array}$ & $\begin{array}{l}\text { past oriented } \\
\text { avoiding risks } \\
\text { interested in maintaining } \\
\text { satisfied } \\
\text { waits for need to surface }\end{array}$ \\
\hline $\begin{array}{l}\text { forcefully acts } \\
\text { long-term oriented } \\
\text { on the cutting edge } \\
\text { takes initiative and encourages } \\
\text { others to take initiative } \\
\text { conceptual }\end{array}$ & $\begin{array}{l}\text { slow to act } \\
\text { short-term oriented } \\
\text { plays it safe } \\
\text { conforms and encourages others to } \\
\quad \text { conform } \\
\text { pragmatic }\end{array}$ \\
\hline $\begin{array}{l}\text { concerned with high standards } \\
\text { comfortable with change } \\
\text { willing to make waves } \\
\text { broad interests } \\
\text { willing to invest }\end{array}$ & $\begin{array}{l}\text { concerned with average performance } \\
\text { uncomfortable with change } \\
\text { unwilling to make waves } \\
\text { narrow interests } \\
\text { avoiding investing }\end{array}$ \\
\hline $\begin{array}{l}\text { growth conscious } \\
\text { willing to take a stand } \\
\text { transforming } \\
\text { comfortable with shifts in power } \\
\text { visionary }\end{array}$ & $\begin{array}{l}\text { stability conscious } \\
\text { preferring to let another try first } \\
\text { conforming } \\
\text { uncomfortable with shifts in power } \\
\text { reactionary }\end{array}$ \\
\hline $\begin{array}{l}\text { ahead of the pack } \\
\text { freeing people-the sky is the } \\
\text { limit }\end{array}$ & $\begin{array}{l}\text { with the pack } \\
\text { restricting people-boundaries } \\
\text { cherished }\end{array}$ \\
\hline $\begin{array}{l}\text { comfortable even without limits } \\
\text { interested in moral implications } \\
\text { asking:what if? }\end{array}$ & $\begin{array}{l}\text { comfortable only with limits } \\
\text { interested mostly in bottom line } \\
\text { saying: if it ain't broke, don't fix it! }\end{array}$ \\
\hline $\begin{array}{l}\text { concerned beyond expressed needs } \\
\text { (love, compassion, and concern } \\
\text { for others) }\end{array}$ & addresses only expressed needs \\
\hline $\begin{array}{l}\text { comfortable with pressure } \\
\text { comfortable with shifts in } \\
\text { expectations } \\
\text { makes fundamental changes } \\
\text { encourages others to take } \\
\text { leadership } \\
\text { involved beyond job description } \\
\text { duties }\end{array}$ & $\begin{array}{l}\text { avoiding pressure situations } \\
\text { uncomfortable with shifts in } \\
\text { expectations } \\
\text { makes only minor changes } \\
\text { discourages others from taking } \\
\text { leadership } \\
\text { involved only in job description } \\
\text { duties }\end{array}$ \\
\hline
\end{tabular}




\section{APPENDIX 3--PAIRS OF CONTRASTING STATEMENTS}

The odd items below are the 23 Transformational statements, while the even items are the 23 Transactional statements. * In Section One, Part One of the questionnaire each item is preceded by the words "IN MY ESTIMATION, A SUCCESSFUL PASTOR...," while in Section Two each item is preceded by the words "IN MY ESTIMATION, AN UNSUCCESSFUL PASTOR..."

1 considers the future in decisions

3 sometimes takes risks

5 is concerned with growth

7 is innovative

9 is inquisitive

11 focuses on long-term

13 encourages change

15 makes big changes

17 provides permission to take risks

19 is comfortable without guidelines
2 considers the past in decisions

4 rarely takes risks

6 is concerned with stability

8 is satisfied

10 has a wait and see attitude

12 focuses on short-term

14 encourages stability

16 makes small changes

18 warns against taking risks

20 is comfortable with guidelines

21 sometimes encourages shifts in power

22 usually discourages shifts in power

23 frees people to make own boundaries

24 frees people by setting boundaries

25 says "cast your bread upon the waters"

26 says "don't count your chickens before they hatch"

27 is concerned with needs you haven't expressed

28 is concerned with needs you have expressed

29 is fairly free to express love

30 is fairly modest about expressing love

31 is fairly free to express compassion

32 is fairly modest about expressing compassion

33 is fairly free to express concern for you

34 is fairly modest about expressing concern for you

35 is comfortable with pressure situations

36 avoids pressure situations

37 is comfortable with shifts in expectations

38 avoids shifts in expectations

39 is interested in doing better things

40 is interested in doing things better

41 encourages others to take leadership

42 encourages others to respect leadership

43 is interested in changing or transforming

44 is interested in preserving or stabilizing

45 is involved beyond his job description

46 is involved in his job description

*In the earlier study (Bray, 1989), one pair of items, the "Love Factor," was listed in the Coding Manual as "is concerned beyond expressed needs (love, compassion, and concern for others)" for the Transformational statement and "addresses only expressed needs" for the Transactional statement. For the present study, this pair of items was expanded to 3 pairs of contrasting statements: items 29 and 30, items 31 and 32, and items 33 and 34 above. 


\section{APPENDIX 4: INFORMED CONSENT}

Dear Prospective Participant:

I am a graduate student in Psychology at the University of Rhode Island, as well as, a Baptist minister. I would like to enlist your cooperation in a research project about church relationships. I am asking that you fill out the attached questionnaire; this will take approximately 25 minutes of your time; there is no risk to you. I think you will find it interesting.

Your name will not be connected in any way with your responses to the questions asked. Your answers are completely ANONYMOUS and confidential and are being solicited only for the purposes of this research project. If you decide after you have begun to participate that you would not like to continue, you may stop at any time.

If you agree to take part in this research please sign the INFORMED CONSENT FORM at the bottom of this page. This form will go directly into a separate file and will never be associated with your answers. There is a place on the form below where you may indicate if you would like a summary of my findings.

Sincerely,

$$
\text { Rev. James L. Bray }
$$

\section{INFORMED CONSENT FORM}

I have read the above and agree to participate in the research described.

$\overline{\text { (name) }}-\frac{}{\text { (date) }}$

please send me a summary report there is no need to send me a summary report. 


\section{APPENDIX 5-CODING CHECK INSTRUCTIONS}

Thank you for agreeing to help me code responses.

Attached there are 30 responses to the following question.

"During the course of a pastorate sometimes tensions or conflicts arise over leadership issues. With this in mind, please complete the following: Parishioners and pastors would have less tension (conflict), if pastors (in their leadership role) would concentrate less on

and concentrate more on

You will notice that there are two opportunities for those who answered the question to respond: the "concentrate less on" portion and the "concentrate more on" portion. Label each portion, if possible. Responses that do not fit either of the three above categories are to be left unlabeled. Some responses might receive more than one label.

Responses are to be labeled "Congregation focused" (write CF to the left of the response), "Spiritual Domain" (write SD to the left of the response), or "Controlling" (write C to the left of the response).

Responses are to be labeled "Congregation focused" when they indicate there would be less tension if the pastor would FOCUS ON THE CONGREGATION and/or NOT FOCUS ON ONE OR MORE OF THE FOLLOWING: PROGRAMS, GOALS, IDEAS, OR CONFLICT); an example of a response in this category is: "concentrate more on loving the people."

Responses are to be labeled "Spiritual Domain" when they indicate there would be less tension if the pastor would MAJOR ON ONE OR MORE OF THE FOLLOWING: THE BIBLE, PREACHING, TEACHING, PRAYER, THE EXAMPLE OF JESUS, OR GUIDANCE OF GOD; an example of a response in this category is: "... concentrate more on the Word taught to us through the Bible."

Responses are to be labeled "Controlling" when they indicate there would be less tension if the pastor would BE LESS CONTROLLING, LESS POWER HUNGRY, OR LESS DEMANDING); an example of a response in this category is: "...concentrate less on pushing their plan." 


\section{APPENDIX 5-CODING CHECK INSTRUCTIONS (cont.)}

1 Concentrate less on the guidelines that are set forth for him. Sometimes the pastor thinks only of his job description.

Concentrate more on what parishioners needs are.

2 Concentrate less on doing everything themselves.

Concentrate more on involving all members of the church in activities; also, in administration, where feasible.

3 Concentrate less on getting involved in serving on boards and committees of organizations outside of the church. Less giving sermons on psychology or current events.

Concentrate more on serving and ministering to the spiritual needs of the people and preaching the gospel.

4 Concentrate less on conflicts

Concentrate more on using the Bible to guide and direct their problems.

5 Concentrate less on having tunnel vision, seeing only their view or desire.

Concentrate more on the church family's desire and reason for it. Seek ways to see underlying needs producing desires of same.

6 Concentrate less on conventional routines

Concentrate more on prayer

7 Concentrate less on controlling the entire parish in the mind set and trying to talk down to the congregation; he is human also

Concentrate more on working to get the people together to understand he is not trying to control them. He is trying to be a leadership figure for the good of all.

8 Concentrate less on outward circumstances

Concentrate more on spiritual strengthening of the church body and discipling and discipline on a day to day basis.

9 Concentrate less on the issue to do it their way--or the way they think it should be Concentrate more on handling it the way Jesus would with love and understanding

10 Concentrate less on personality idiosyncrasies

Concentrate more on doctrine, teaching teachers, motivating growth and constructive change

11 Concentrate less on things and thoughts of the world views on certain controversy Concentrate more on God's attitude on church problems

12 Concentrate less on personal opinions and what is perceived as popular Concentrate more on what the Bible says and what God would have them do

13 Concentrate less on how things have always been done in past Concentrate more on current needs of the church

14 Concentrate less on the position of the one in authority Concentrate more on how the Lord would have handled the situation and presenting their beliefs in love and patience 
APPENDIX 5-CODING CHECK INSTRUCTIONS (cont.)

15 Concentrate less on issuing(?) leadership

Concentrate more on letting the people choose what they would like to take on for leadership

16 Concentrate less on personal opinions

Concentrate more on exegesis of Bible to answer questions

17 Concentrate less on pressing for their own goals without enlisting their people and giving the "whys"

Concentrate more on showing them reasons for the direction he's seeking to lead

18 Concentrate less on trying to do it all himself, don't insist on "traditions"

Concentrate more on delegating responsibility, being flexible

19 Concentrate less on trying to get his pet issues developed or adopted

Concentrate more on leading his people into following Scriptural principles

20 Concentrate less on being right

Concentrate more on being Biblical

21 Concentrate less on minor issues, strong lobbying

Concentrate more on 1) seed planting, 2) doing homework on proper communication, 3) hearing out opposing views--after things cool down//giving ready at later date (after proper contemplation), 4) avoiding polarization

22 Concentrate less on their own mind set and having it always their way and not being teachable themselves

Concentrate more on loving the people, meeting other's needs and having a teachable spirit

23 Concentrate less on programs

Concentrate more on people

24 Concentrate less on demanding their position be embraced before the groundwork has been laid

Concentrate more on patience/perseverance and process in working through difficult issues

25 Concentrate less on how the people feel about them

Concentrate more on pleasing the Lord, preaching and teaching the word of God

26 Concentrate less on trying to correct or improve every internal problem

Concentrate more on ministering effectively in reaching the community with a strategy which leads a congregation to look less upon itself

27 Concentrate less on being concerned about congregation listening to him

Concentrate more on building loving relationships and trust with congregation

28 Concentrate less on position and power

Concentrate more on being strong leaders yet gentle pastors 


\section{APPENDIX 5-CODING CHECK INSTRUCTIONS (cont.)}

29 Concentrate less on lording over the people as a "benevolent dictator" in forcing change a limiting (sic)

Concentrate more on modeling a vision for the future and guiding the people to capture the vision as their own

30 Concentrate less on things

Concentrate more on people 
Under "Resistance to Change" Klubnik records the following responses:

Status quo thinking-unprogressive.

The slowness of churches to act.

The power of tradition.

Decision-making slow.

The inertia that frustrates new and creative ideas for growth.

The weight of tradition in the church.

Commitments to denominations rather than to the Lord.

Slowness of Christians to be flexible.

Lack of response to new ideas.

Dealing with illogical, immature, tradition-bound people.

People who refuse to change.

Under "Board conflict" Klubnik records the following responses:

Not being counseled with regard to my salary needs or expectations.

Not being able to motivate my board-I have a non-rotating board.

Working with the official board when members lack vision.

Working with a board with both rural and city mentality.

Tension between self and other board members.

The bureaucracy and speed of decision-making in the church is frustratingly slow.

Under "Pleasing People" Klubnik records the following responses:

Being forced to relate to all kinds of people.

Desire for 'instant success' by congregation.

Gossip and judgmentalism of the people.

Being misunderstood by some people.

Being the center of so much criticism.

Touchy people.

Occasional strife over personalities and petty things.

Dogmatic individuals who try to run the ministry for me.

Being evaluated in non-moral areas- "application Christianity."

People problems-mainly discouragement.

Trying to keep everybody happy.

Oversensitivity of Christians--so easily hurt or offended.

Tension of not being able to please the board.

Being misunderstood.

Potential blow-ups at the annual congregational meeting.

Under "Discouragement" Klubnik records the following responses:

Lack of encouragement by congregation.

Feeling at times that one really doesn't accomplish much.

It seems God isn't doing anything significant through me.

Emotional burnout.

Dealing with the feeling that I'm never finished.

Not getting more (be able to) do all I want to do. 


\section{BIBLIOGRAPHY}

Andriessen, Erik J. H. and Drenth, Pieter, J. D. (1984). Leadership: theories and models. In P. J. Drenth, H. Thierry, P. J. Willems and D. J. de Wolff (Eds.), Handbook of work and organizational psychology. (pp. 481-520). New York: John Wiley and Sons.

Bandura, Albert (1986). Social foundations of thought and action: A social cognitive theory. Englewood Cliffs, NJ: Prentice-Hall.

Bass, Bernard M. (Ed.) (1981). Stogdill's handbook of leadership: a survey of theory and research. New York: The Free Press.

Bass, Bernard M. (1985a). Leadership: good, better, best. Organization- Dynamics. Vol. 13(3), 26-41.

Bass, Bernard M. (1985b). Leadership and performance beyond expectation. New York: The Free Press.

Bennis, Warren and Nanus, Burt (1985). Leaders: the strategies for taking charge. New York: Harper \& Row.

Bible--New international version. (1983). Grand Rapids, Michigan: Zondervan.

Bray, James L. (1989). "Transformational and transactional church leadership perspectives and their impact on the duration of pastoral tenure." University of Rhode Island: Thesis.

Brown, Collin (Ed.) (1975). The new international dictionary of New Testament theology, Vol. 1. Grand Rapids, Michigan: Zondervan Publishing Co.

Brown, M. Diane (1987). Leadership and organization transformation: a competency model. Fielding Institute-Dissertation.

Burns, James MacGregor. (1978). Leadership. New York: Harper and Row.

Callahan, Kennon. (1990). Effective church leadership. San Francisco: Harper and Row.

Cattell, R. B. (1966). The scree test for the number of factors. Multivariate behavioral research, 1, 245-276. 
Cohen, J. A. (1960). A coefficient of agreement for nominal scales. Educational and Psychological measurement, 20, 37-46.

Deal, Terrence E. and Kennedy, Allan A. (1982). Corporate Cultures: the rites and rituals of corporate life. Reading, Mass: Addison-Wesley Pub. Co.

Deluga, Ronald J. (1988). Relationship of transformational and transactional leadership with employee influencing strategies. Group \& Organization Studies, Vol. 8 (4), 456-467.

Freidman, Edwin H. (1986). Emotional process in the marketplace: the family therapist as consultant with work systems. In Systems consultation: a new perspective for family therapy. Wynne, Lyman C., McDaniel, Susan H., \& Weber, Timothy T. (Editors). N.Y., N.Y.: Guildford Press.

Freiberg, Kevin L. (1987). The heart and spirit of transformational leadership: a qualitative case study of Herb Kelleher's passion for southwest airlines (Texas). U. of San Diego-Dissertation.

Gibbons, Tracy C. (1986). Revisiting the question of born vs. made: toward a theory of development of transformational leaders. Fielding Institute-Dissertation.

George, Carl F. (1987). The berry bucket balance. Leadership, Vol. $\underline{8}(4), 52-57$.

Giuliano, Anthony Joseph. (1988). The meaning in caregiving scale: factorial and conceptual dimensions. University of Rhode Island: A Thesis Proposal.

Goldhaber, Gerald M. (1990). Organizational communication (5th Edition): Dubuque, Iowa: Wm. C. Brown Publishers.

Gordon, Judith R. (1987). A diagnostic approach to organizational behavior, (Second Edition). Boston: Allyn and Bacon.

Harris, Philip R. (1985). Management in transition. San Francisco: Jos sey-Bass.

Hersey, Paul and Blanchard, Kenneth H. (1972). Management of organizational behavior, (Second Edition). Englewood Cliffs, N.J.: Prentice-Hall.

Hollander, Edwin P. (1985). Leadership and power. In The handbook of social psychology. 
(Third Edition; Vol. 2). New York: Random House, 485-537.

Howard, Dale Dwight (1985). The pastor as leader: personality strengths and church expectations, factors, in pastoral length of ministry with the individual church. U. of Alabama-Dissertation.

Hybels, Bill, and Briscoe, Stuart, and Robinson, Haddon (1989). Mastering Contemporary Preaching. Seattle, WA: Multnomah.

Johnson, Wesley M. (1987). The development of a series of workshops to deal with issues relating to involuntary pastoral termination. Eastern Baptist Theological Seminary-Dissertation.

Kiefer, C. and Senge, P. (1984). Metanoic organizations. In J. D. Adams (Ed.) Transforming work. (pp. 69-84), Alexandria, VA: Miles River Press. Klubnik, James J. (1984). A survey analysis of conflicts in role expectations of dallas theological seminary alumnipastors and their congregations. Dallas Theological Seminary-Dissertation.

Krippendorff, Klaus. (1980). Content analysis: an introduction to its methodology. Beverly Hills: Sage Publications, Inc.

Levy, Amir and Merry, Uri. (1986). Organizational transformation: ap proaches, strategies, theories. New York: Praeger.

Pargament, Kenneth I., Echemendia, Ruben J., Johnson, Steven, Cook, Paul, McGath, Cheryl, Myers, Jennifer G., and Brannick, Michal. (1987). The conservative church: psychosocial advantages and disadvantages. American Journal of Community Psychology, Vol. 15(3), 269-286.

Schaller, Lyle E. (1975). Hey, that's our church. Nashville, Tennessee: Abington.

Singer, Ming S. (1985). Transformational vs. transactional leadership: a study of New Zealand company managers. Psychological Reports, 57, 143-146.

Singer, M. S. and Singer, A. E. (1986). Relation between transformational vs transactional leadership preference and subordinates' personality: an exploratory study. Perceptual and Motor Skills, Vol. 62, 775-780. 
Tichy, Noel M. and Devanna, Mary Anne (1986a). The transformational leader. Training and Development Journal, July, 27-32.

Tichy, Noel M. and Devanna, Mary Anne (1986b). The transformational leader. New York: John Wiley \& Son, Inc.

Tichy, N. M. and Ulrich, D. O. (1984). A call for the transformational leader. Sloan Management Review, 26, 59-68. 